\title{
Regionalentwicklung IM BURgenLAND UND In WeStungarn WÄHREND DES 20. JAHRHUNDERTS - EIN VERGLEICH ${ }^{1)}$
}

\author{
Róbert GYŐRI, Budapest, und Ferenc JANKÓ, Sopron/Ödenburg*
}

mit 7 Abb. und 3 Tab. im Text

\section{INHALT}

Summary 216

Zusammenfassung

1 Fragestellung

2 Theoretische Grundlagen ............ 218

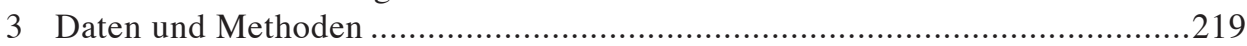

4 Die Rolle des historischen Westungarns in der Regionalstruktur Ungarns zu Beginn des 20. Jahrhunderts

5 Entwicklungsunterschiede im historischen Westungarn zu Beginn

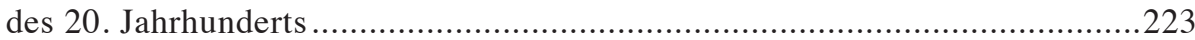

6 Auswirkungen der Grenze von Trianon auf den Einzugsbereich der Städte.....225

7 Entwicklung der Regionalstruktur vom Ersten Weltkrieg bis in die

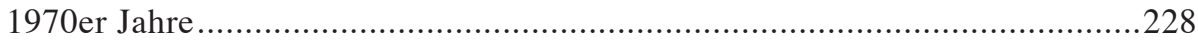

8 Die Regionalentwicklung von den 1970er Jahren bis heute .......................232

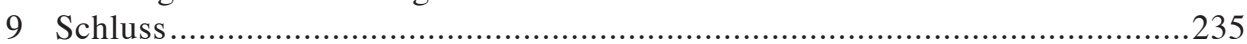

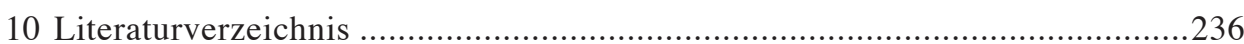

1) Für diese Untersuchung wurden auch Ergebnisse der OTKA-Forschung Nr. T69138 (Ungarisches Grundprogramm für wissenschaftliche Forschung) verwendet.

* Dr. Róbert GYôRI, Institut für Geographie und Geowissenschaften, Eötvös-Loránd-Universität, Pázmány P. sétány 1/c, H-1111 Budapest; e-mail: gyorirobert@caesar.elte.hu,http://geogr.elte.hu/; Dr. Ferenc JANKÓ, Institut für Internationale und Regionale Ökonomie, Universität Westungarn, Erzsébet u. 9, H-9400 Sopron; e-mail: frk@ktk.nyme.hu,http://nrgit.ktk.nyme.hu 


\section{Summary}

Regional development in Burgenland and West Hungary during the $20^{\text {th }}$ century $-A$ comparison

Based on census data as of 1910, 1960/61 and 2001 we examine, in which way the new border between Austria and Hungary established after World War I became an economic and developmental divide, i.e. how different the contemporary Burgenland and West Transdanubia developed.

With some exaggeration it is possible to say that a former periphery has turned into a central region, while a former centre has become a periphery. During the era of Communism a steep west-east gradient had emerged in the region, while the traditional north-south disparity continued to exist.

During transformation and even more so after Hungary's EU accession, the obstacle of a border fell. After 1990 patterns of regional disparities in Hungary changed within a few years, and West Transdanubia reached within Hungary leading positions in every dimension of development. This meant in fact the re-establishment of regional disparity patterns as they had existed before Word War II. It became evident that the era of Communism was just a short intermezzo. But it was sufficient to provide West Transdanubia with a notable deficit in modernisation compared to contemporary Burgenland.

Apart from macroeconomic circumstances, a more intensive convergence towards the old and new centre Vienna may probably be the best way towards equalisation.

\section{Zusammenfassung}

Auf der Grundlage der Daten der Volkszählungen 1910, 1960/61 und 2001 untersuchen wir, inwiefern die nach dem Ersten Weltkrieg neu gezogene österreichischungarische Grenze zu einer Trennlinie im Hinblick auf Wirtschaft und Fortschritt wurde, in welcher Weise und wie unterschiedlich sich also das vormalige Westungarn, das heutige Burgenland und das heutige Westransdanubien entwickelten.

Mit gelinder Übertreibung könnte man sagen, dass aus einer früheren Peripherie eine Zentralregion wurde, während ein früheres Zentrum zur Peripherie absank. In der Ära des Kommunismus entwickelte sich in der Region ein deutliches West-Ost-Gefälle, während sich am traditionellen Nord-Süd-Gefälle wenig änderte.

Während der Transformation und besonders nach dem EU-Beitritt Ungarns fiel das Hindernis der Grenze. Nach 1990 änderte sich das Muster räumlicher Disparitäten in Ungarn innerhalb weniger Jahre, und in Ungarn erreichte Westtransdanubien innerhalb kurzer Zeit in jeder Hinsicht eine führende Stellung. Das bedeutete aber nur die Wiederherstellung der Verhältnisse vor dem Zweiten Weltkrieg, und die Ära des Kommunismus erscheint lediglich als ein kurzes Intermezzo. Sie reichte aber aus, um Westransdanubien gegenüber dem heutigen Burgenland einen bedeutenden Modernisierungsrückstand zuzufügen.

Abgesehen von makroökonomischen Einflüssen wird wohl eine möglichst intensive Annäherung an das alte und neue Zentrum Wien die beste Möglichkeit sein, den Rückstand wieder aufzuholen. 


\section{Fragestellung}

Die nach dem Ersten Weltkrieg neu gezogene österreichisch-ungarische Grenze kam durch Gebietsverschiebungen zwischen Verlierern des Weltkriegs zustande. Es war auch die einzige Grenzänderung, durch die Österreich Gebiete dazu gewann. Das erklärt teilweise, dass diese Grenze aus österreichischer Sicht wenig problematisiert wurde und viel weniger als die neuen Grenzen in Tirol, Kärnten und der Steiermark die Aufmerksamkeit österreichischer Geographen auf sich zog. (z.B. PAschinger 1919; Sölch 1923; Mitterbach 1949; neulich Penz 2008).

Aus ungarischer Sicht war diese Grenzziehung besonders aus zwei Gründen bemerkenswert. Erstens deshalb, weil die ungarische Diplomatie nur an diesem Abschnitt der auch sonst völlig neuen ungarischen Staatsgrenzen eine bedeutende Korrektur erwirken konnte, indem sie die aus ungarischer Sicht erfolgreiche Volksabstimmung um Ödenburg [Sopron/Ödenburg]) $)^{2)}$ durchsetzte. Ein zweiter Grund war, dass unter allen ungarischen Grenzabschnitten an dieser Grenze dem ethnischen Bewusstsein noch am meisten Rechnung getragen wurde.

Nichtsdestotrotz wurde diese Grenze erst nach 1946 durch die Aussiedlung des überwiegenden Teils der Ungarndeutschen aus Westtransdanubien [Nyugat-Dunántúl] zu einer scharfen ethnischen und sprachlichen Grenze - jedoch nur im Hinblick auf Deutschsprachige und Ungarn, während Kroaten weiterhin beiderseits der Grenze ansässig blieben. Mit dem Eisernen Vorhang wurde sie auch zu einer politischideologischen Scheidelinie.

In unserer Arbeit wollen wir untersuchen, wie sich das durch die Grenze von Trianon geteilte vormalige Westungarn, das heutige Burgenland und das heutige Westtransdanubien, seither entwickelt haben.

Nach einer Diskussion der theoretischen und methodischen Grundlagen werden wir zunächst die Situation des ganzen Westungarns im Königreich Ungarn beleuchten. Danach präsentieren wir die Ausgangssituation unserer Untersuchung, also den Entwicklungsstand der Region vor den neuen Grenzen des Vertrags von Trianon. Wir gehen dann auf die Auswirkungen dieser Grenzen auf den Einzugsbereich der Städte ein - ein entscheidender Faktor in der späteren Regionalentwicklung. Schließlich stellen wir die Regionalentwicklung in der zweiten Hälfte des 20. Jahrhunderts dar.

\footnotetext{
2) Für geographische Objekte auf ungarischem Gebiet werden in diesem deutschsprachigen Text gebräuchliche deutsche Namen verwendet, wobei die Endonyme bei der ersten Erwähnung des Objekts in eckigen Klammern stehen. Sind wie im Fall von Ödenburg Namen in mehreren Sprachen amtlich, so erscheinen beide Namenformen durch Schrägstrich getrennt. Geographische Objekte auf heute österreichischem Gebiet werden mit ihren amtlichen Namen bezeichnet, was im Fall amtlicher Zweisprachigkeit die Nennung von zwei durch Schrägstrich getrennten Namenformen bedeuten kann (z.B. Siegendorf/Cindrof). Besonders im Zusammenhang mit der Periode vor dem Ersten Weltkrieg werden aber für Objekte im heutigen Burgenland in runden Klammern auch die ungarischen Namen genannt wie sie bis dahin amtlich waren.
} 


\section{Theoretische Grundlagen}

Im Mittelpunkt unserer Untersuchung steht also die regionale Entwicklung eines Grenzraumes, und im Zusammenhang damit verwenden wir die Begriffe „Entwicklung“ und „Modernisierung“.

„Entwicklung“ war im 20. Jahrhundert ein Schlüsselbegriff der wirtschaftswissenschaftlichen und sozialpolitischen Literatur. Seine Wurzeln gehen auf den politischen und wirtschaftlichen Liberalismus, die Diskussion um geschützten und freien Markt, den Marxismus, die sozialdarwinistische Auffassung von Evolution sowie auf die anti-kolonialistische Verteidigung von Kultur und nationaler Selbstbestimmung zurück (CHARI 2009). Auch in der geographischen Diskussion hat er sich weit verbreitet. Es sei hier nur an das Landschafts- oder an das Raumparadigma oder an die Begriffe „Siedlungs-, Landschafts- oder Regionalentwicklung“ erinnert.

Der Forschungsansatz der Regionalentwicklung hat sich in Zusammenhang mit dem sogenannten "spatial turn" nach dem Zweiten Weltkrieg konkretisiert, nachdem die traditionelle regionale Geographie oder Länderkunde in den Hintergrund getreten (Blotevogel 1996) und in den 1970er Jahren die geographische Entwicklungsforschung begründet worden war (BoHLE 2007).

Die Wirtschaftswissenschaften haben zum Begriff „Entwicklung“ wesentlich beigetragen. Es seien hier nur das Entwicklungsmodell von Rostow, die WiLliamson-Hypothese, oder das Zentrum-Peripherie-Modell von Friedmann (neulich zusammengefasst von HAVLIČEK et al. 2008) erwähnt (HAGGETT 2001, S. 556-567; EzCURRA \& RAPÚN 2006).

Die mehrfach kritisierte Entwicklungstheorie von Rostow ist zur Basis für den Kampf gegen die Armut der Entwicklungsländer, aber auch für die Geopolitik des Kalten Krieges geworden. An ihr wird kritisiert, dass sie Entwicklung und Transformation als Nachvollzug des Weges der Industrieländer begreift. Gemäß Modernisierungstheorie wird dieser Prozess aber v.a. von Traditionen, gemäß Dependenztheorie durch Abhängigkeiten und deformierte Sozial- und Wirtschaftsstrukturen behindert (BoHLE 2007; S. 798-799, ChARI 2009). Es ist kein Zufall, dass der Begriff „Modernisierung” oft als Synonym für Entwicklung im evolutionistischen Sinn benutzt wird. Man versteht darunter die Loslösung von Traditionen und die Anpassung an eine marktwirtschaftliche Ordnung und an damit verbundene Lebensformen (BELuszKy 2000; STROHMAYER 2009).

Die Kritik am Entwicklungsmodell von Rostow und an der Modernisierungstheorie führten zur Idee des ,,post- oder anti-development”. Diese verwirft beide mit der Begründung, „Entwicklung” hätte den Entwicklungsländern nur Armut und Hunger gebracht. Der soziale Konstruktivismus stellt selbst die Unterentwicklung der Dritten Welt in Frage (CORBRIDGe 2009).

Im Falle eines Grenzgebietes in Mitteleuropa erhebt sich v.a. die Frage, auf welche Weise staatliche und regionale Einflussfaktoren oder städtische Zentren die Regionalentwicklung auf beiden Seiten der Grenze beeinflussten (SEGER 1993, S. 1-6). Sie ist bezogen auf Westungarn nach dem Zweiten Weltkrieg jedenfalls am besten mithilfe der Dependenztheorie zu erklären: der „Kolonisator” des Landes, die Sowjetunion, importierte eine Politik, die zu einer deformierten Sozial- und Wirtschaftsstruktur führte und das Aufschließen zu den westlichen Industrieländern erschwerte. 
In unserem regionalen Systemvergleich untersuchen wir die traditionellen Merkmale der Entwicklung (BRUGGER 1984) und einige Indikatoren der Modernisierung wie Demographie und Infrastruktur. Wir verwenden also die Begriffe der Entwicklung und Modernisierung im engeren Sinn. Unter regionalen Disparitäten verstehen wir räumliche Differenzen in Sozialstruktur und Lebensniveau.

\section{Daten und Methoden}

Unter Westungarn im historischen Sinn verstehen wir die Komitate [megye] Wieselburg [Moson], Raab [Győr], Ödenburg [Sopron] und Eisenburg [Vas] sowie die Bezirke [járás] Pápa und Devecser des Komitats Veszprém. Den nach dem Ersten Weltkrieg um das Burgenland verkleinerten ungarisch gebliebenen Teil Westungarns bezeichnen wir als Westtransdanubien. ${ }^{3)}$

Um die Regionalentwicklung seit der Zeit vor dem Ersten Weltkrieg statistisch zu erfassen, haben wir drei Zeitpunkte gewählt: das Jahr 1910 als Zeitpunkt vor der Trennung; die Volkszählungen der Jahre 1960 (Ungarn) bzw. 1961 (Österreich) als Zeitpunkt eines beginnenden "Take-offs" im Burgenland, später auch in Ungarn; und 2001 als das bisher letzte Volkszählungsjahr nach der politischen Wende.

Mit diesen Volkszählungsdaten haben wir Datenbasen erstellt, aus denen nach Kartierungen und Analysen jene Merkmale ausgewählt wurden, die sich zur Illustration der Regionalentwicklung als am besten geeignet erwiesen. Für 1910 wurden sechs, für 1960/61 fünf, für 2001 vier Merkmale ausgewählt (vgl. Tab. 1).

Die Verbindung der Daten zu einem Index erfolgte mit einfachen statistischen Methoden: die Variablen wurden einzeln standardisiert; ${ }^{4)}$ aus den standardisierten Werten wurde das mathematische Mittel errechnet; nach einer ungewichteten Zusammenführung erhielten wir den komplexen Entwicklungsindex.

Natürlich mussten für 1960/61 und 2001 andere Merkmale als für 1910 herangezogen werden, weil die Statistik andere Merkmale erhob. Doch erfassen die verschiedenen Merkmale ähnliche Sachverhalte. Für die Zeitpunkte 1960/61 und 2001 war die Auswahl auch durch die Unterschiede zwischen ungarischer und österreichischer Volkszählung eingeschränkt.

Daneben wurden auch andere quantitative Methoden verwendet. So wurde mithilfe des Gravitationsmodells die Auswirkung der Grenze auf den Einzugsbereich der Städte untersucht und für eine zusammenfassende Darstellung der regionalen Raumstruktur die sogenannte Bevölkerungsschwerpunkt-Methode verwendet.

\footnotetext{
3) Das Gebiet des Bezirks [járás] Devecser scheint in heutigen Statistiken unter dem Namen der Kleinregion Ajka auf. Der frühere Bezirk Muraszombat [Murska Sobota] im früheren Komitat Eisenburg [Vas megye], der heute in Slowenien liegt, fließt in unsere Berechnungen zur Nachkriegszeit nicht mehr ein. 4) Standardisiert auf Durchschnitt und Streuung unter Anwendung der Formel $\left(\mathrm{x}_{\mathrm{i}}-\mathrm{x}_{\mathrm{a}}\right) / \mathrm{s}_{\mathrm{x}}$
} 


\begin{tabular}{|c|c|}
\hline Merkmal & Quelle \\
\hline $\begin{array}{l}\text { Anteil der Bevölkerung über sechs Jahren, der lesen und schreiben } \\
\text { kann, } 1910\end{array}$ & MKKSH 1912a \\
\hline $\begin{array}{l}\text { Anteil der Wohnhäuser aus Stein oder Ziegeln oder mit einem } \\
\text { Stein- oder Ziegelfundament, } 1910\end{array}$ & MKKSH 1912a \\
\hline $\begin{array}{l}\text { Anteil der Berufstätigen, die in der Landwirtschaft beschäftigt sind, } \\
1910\end{array}$ & MKKSH 1913 \\
\hline $\begin{array}{l}\text { Anteil der Verstorbenen, die vor ihrem Ableben ärztliche Hilfe in } \\
\text { Anspruch genommen haben, 1901-1910 }\end{array}$ & MKKSH 1912b \\
\hline Rate der Migrationsbewegungen, 1901-1910 & MKKSH 1912b \\
\hline $\begin{array}{l}\text { Reines Katastereinkommen pro Beschäftigtem in der Landwirtschaft, } \\
1910\end{array}$ & MKP 1914a-e \\
\hline $\begin{array}{l}\text { Veränderung der Bevölkerungszahl, in Ungarn zwischen } 1949 \text { und } \\
\text { 1960, in Österreich zwischen } 1951 \text { und } 1961\end{array}$ & \multirow{5}{*}{$\begin{array}{l}\text { KSH } 1960 \mathrm{a}-\mathrm{d} \text {; } \\
\text { ÖSTAT 1963a-b }\end{array}$} \\
\hline Anteil der nicht in der Landwirtschaft Beschäftigten, 1960/61 & \\
\hline Anteil der Wohnungen, die mehr als ein Zimmer haben, 1960/61 & \\
\hline $\begin{array}{l}\text { Anteil der ans Stromnetz angeschlossenen bewohnten Wohnungen, } \\
\text { 1960/61 }\end{array}$ & \\
\hline Anteil der nach 1945 erbauten Wohnungen, 1960/61 & \\
\hline $\begin{array}{l}\text { Änderung der Bevölkerungszahl, in Ungarn zwischen } 1990 \text { und 2001, } \\
\text { in Österreich zwischen } 1991 \text { und } 2001\end{array}$ & \multirow{4}{*}{$\begin{array}{l}\text { KSH } 2002 a-c ; \text { SA } \\
2002 a-c, 2004\end{array}$} \\
\hline Anteil der Beschäftigten im tertiären Sektor, 2001 & \\
\hline Anteil der bewohnten Wohnungen mit vier oder mehr Zimmern, 2001 & \\
\hline $\begin{array}{l}\text { Anteil der Neubauten an den vorhandenen Wohnungen, in Ungarn } \\
\text { zwischen } 1990 \text { und 2001, in Österreich zwischen } 1991 \text { und } 2001\end{array}$ & \\
\hline
\end{tabular}

Tab. 1: Merkmale der Entwicklungsindizes für 1910, 1960/61 und 2001

\section{Die Rolle des historischen Westungarns in der Regionalstruktur Ungarns zu Beginn des 20. Jahrhunderts}

Im heutigen Europa nehmen die wirtschaftliche Leistungsfähigkeit, das Volkseinkommen und die Lebensqualität mit der Entfernung vom westlichen Innovationskern ab. Das lässt sich nicht allein damit erklären, dass die Länder des östlichen Europas Jahrzehnte hindurch dem kommunistischen Modell folgten. Es handelt sich vielmehr um ein säkulares Phänomen der europäischen Regionalstruktur, das sich in erster Linie mit dem Zentrum-Peripherie-Modell erklären lässt.

Einige Wirtschaftshistoriker haben versucht, das Bruttoinlandsprodukt der europäischen Länder und manchmal auch von Teilgebieten für historische Zeitpunkte 
näherungsweise zu berechnen (Katus 1979, 1988; Good 1993). ${ }^{5}$ Diese Berechnungen kommen im Großen und Ganzen zum selben Ergebnis: zu Beginn des 20. Jahrhunderts nahm die Wirtschaftsleistung gemessen am Wert des Bruttoinlandsprodukts pro Kopf der Bevölkerung vom Vereinigten Königreich aus in Richtung Osten und Süden kontinuierlich ab; das West-Ost-Gefälle war durch ein ausgeprägtes Nord-Süd-Gefälle ergänzt.

Die Österreichisch-Ungarische Monarchie und innerhalb dieser das Königreich Ungarn fügten sich gut in dieses Schema ein. Etwa zur Zeit des Ausgleichs (1867) betrug das Bruttoinlandsprodukt pro Kopf der Bevölkerung in der österreichischen Reichshälfte $38 \%$ des Werts im Vereinigten Königreich (der Wert im Gebiet des heutigen Österreich lag bei 52,4\%), während es im Königreich Ungarn nicht einmal ein Viertel des britischen Werts erreichte $(22,6 \%)$. Auch auf dem Gebiet des heutigen Ungarns überschritt es diesen Wert nur geringfügig (26,7\% - Good 1993; Katus 1979, S. 961).

Die Zeit des Dualismus war für das Königreich Ungarn eine Aufholperiode. Das Tempo des Wirtschaftswachstums übertraf das der westeuropäischen Staaten, aber auch das der österreichischen Reichshälfte. László KaTus schätzt die Zuwachsrate des Bruttoinlandsprodukts pro Kopf im Königreich Ungarn auf 1,7\% jährlich, David F. Good auf 2\% (für das Gebiet des heutigen Ungarns auf 2,5\%). Innerhalb der Monarchie reduzierten sich damit die regionalen Disparitäten. Das Bruttoinlandsprodukt pro Kopf der ungarischen Reichshälfte entsprach (nach KaTus und Good) 84 bzw. 79\% dessen der österreichischen Reichshälfte, jenes auf dem Gebiet des heutigen Ungarns 65 bzw. $69 \%$ der österreichischen Reichshälfte. Zwar rückte Ungarn nicht wesentlich vor, doch hat es seine Position verbessert und sich dem europäischen Mittelfeld angenähert.

Es stimmt zwar, dass im historischen Ungarn die regionalen Disparitäten weit geringer waren als in der österreichischen Reichshälfte, doch zeigten sich in Wirtschaftsstruktur und Produktivität beträchtliche Unterschiede (KATUs 1988, S. 398-400).

In der Landwirtschaft bildete neben den Naturgegebenheiten, dem Zugang zum Markt und den Besitzverhältnissen vor allem das unterschiedliche Niveau der Landbewirtschaftung einen wichtigen differenzierenden Faktor. Die besten natürlichen Bedingungen für die landwirtschaftliche Produktion boten die Landschaften des Großen Ungarischen Tieflands [Alföld]. Hinsichtlich des Entwicklungsgrades der Landwirtschaft war hingegen Westungarn - das Gebiet des heutigen Burgenlandes eingeschlossen - landesweit führend. Hier war schon zu Ende des 19. Jahrhunderts die Brache verschwunden und durch Fruchtwechsel ersetzt worden. Arbeitsintensive Industriepflanzenkulturen - in erster Linie die Zuckerrübe - nahmen große Flächen ein. Düngemittelverbrauch und Mechanisierung waren hier am weitesten fortgeschritten. In Betrieben aller Größen wurde gleichermaßen fortschrittlich produziert. Es überrascht nicht, dass in Bezug auf den Nettoertrag pro landwirtschaftlich Erwerbstätigem das Komitat Wieselburg [Moson megye] in ganz Ungarn an erster Stelle stand. Das Komitat Raab [Győr megye] und das Komitat Ödenburg [Sopron megye] folgten an 5. bzw. 7. Stelle. Das Komitat Eisenburg [Vas megye] belegte allerdings erst den 21. Platz (Vörös 1988, S. 311-313, 315-319; Nagy 2003, S. 59, 150-156).

\footnotetext{
5) Good (1993) vergleicht und interpretiert seine eigenen Berechnungen und die von Anton KaUSEL, N.F.R. Crafts, Paul Bairoch, Angus Maddison und László Katus.
} 
Die ungarische Industrie war zu Beginn des 20. Jahrhunderts sehr auf Budapest konzentriert. Daneben gab es nur noch einige wichtige Standorte der Schwerindustrie in Rohstoffnähe, so im mittleren Teil Oberungarns, der heutigen Slowakei, sowie im Südwesten des heutigen innerkarpatischen Rumäniens. Zu den industriell entwickelteren Gebieten gehörte aber doch auch Westungarn. Der Anteil der Beschäftigten in der Industrie an der Gesamtzahl der Beschäftigten betrug in der ganzen Region mehr als $20 \%$ - in den Komitaten Raab und Ödenburg (einschließlich der Städte) mehr als $23 \%$. Dem stand auf dem Land ein Durchschnitt von 16,5\% gegenüber. In einigen Industriezweigen hatte Westungarn landesweite Bedeutung erlangt; so in der Lebensmittelindustrie und innerhalb dieser vor allem in der Zuckerproduktion. Im Komitat Ödenburg waren zu Beginn des 20. Jahrhunderts fünf Zuckerfabriken in Betrieb. Das Gleiche galt für die sich rasant entwickelnde Textilindustrie, deren Betriebe um die Jahrhundertwende entstanden. In einigen Städten ergänzten die Schwerindustrie, vor allem der Maschinenbau und die chemische Industrie, die industrielle Palette. Die übrigen Regionen Ungarns fielen dagegen weit ab (KATus 1988, S. 355-358; BelusZKY 2005, S. 436-443).

Daran lässt sich erkennen, dass sich der Stand der Regionalentwicklung innerhalb Ungarns gut in das allgemeine europäische Muster einfügte: ein dominantes WestOst-Gefälle wird durch ein weniger stark ausgeprägtes Nord-Süd-Gefälle ergänzt. In Landwirtschaft und Industrie ragten neben der Hauptstadt Budapest und ihrer Umgebung die westlichen Gebiete Ungarns heraus.

Auch der amerikanische Historiker David F. Good bestätigt diese Erkenntnis für Zeitpunkte zwischen 1870 und 1910. Er berechnete das Bruttoinlandsprodukt pro Kopf der Bevölkerung für die in den 1880er Jahren vom Statistischen Zentralamt (KSH) ausgewiesenen Großregionen. ${ }^{6}$ Die herausragenden Werte des Donau-Theiß-Beckens [Duna-Tisza köze], in dem die Hauptstadt Budapest lag, werden von den drei westlichen Großregionen mit Werten nahe dem Landesdurchschnitt gefolgt. Die östlichen Landesteile des historischen Ungarns fielen dagegen weit ab. Die Schlusslichter bildeten das „Gebiet jenseits des Königswaldes“ [Királyhágóntúl], also Siebenbürgen [Ardeal], und das ungarische Nebenland Kroatien-Slawonien [Hrvatsko-Slavonija/ Horvát-Slavónország] (Good 1993). Leider ist in den Berechnungen Good’s Westtransdanubien nicht eigens ausgewiesen, sondern mit dem „Rechten Donauufer“ [Duna jobb partja] verschmolzen, was seine Berechnungen für unsere Zwecke weniger aussagekräftig macht.

Eine Einschätzung kleinräumigerer Disparitäten wird durch eine Erhebung des Alphabetisierungsgrades nach Verwaltungsbezirken [járás] ermöglicht (vgl. Abb. 1). Sie lässt den Vorsprung der westlichen und mittleren Landesteile Ungarns gut erkennen. Jedoch ist dabei zu berücksichtigen, dass Muttersprache und Religionszugehörigkeit das Bild etwas verzerren, weil sprachliche und religiöse Minderheiten das Ungarische oft weniger gut beherrschten (GYŐRI 2005, S. 103; vgl. auch BELUSZKY 2000).

\footnotetext{
6) Die Grenzen dieser Großregionen decken sich allerdings nur teilweise mit Verwaltungsgrenzen, so dass die von Good (1993) geschätzten Werte mit anderen Berechnungen nur beschränkt vergleichbar sind.
} 


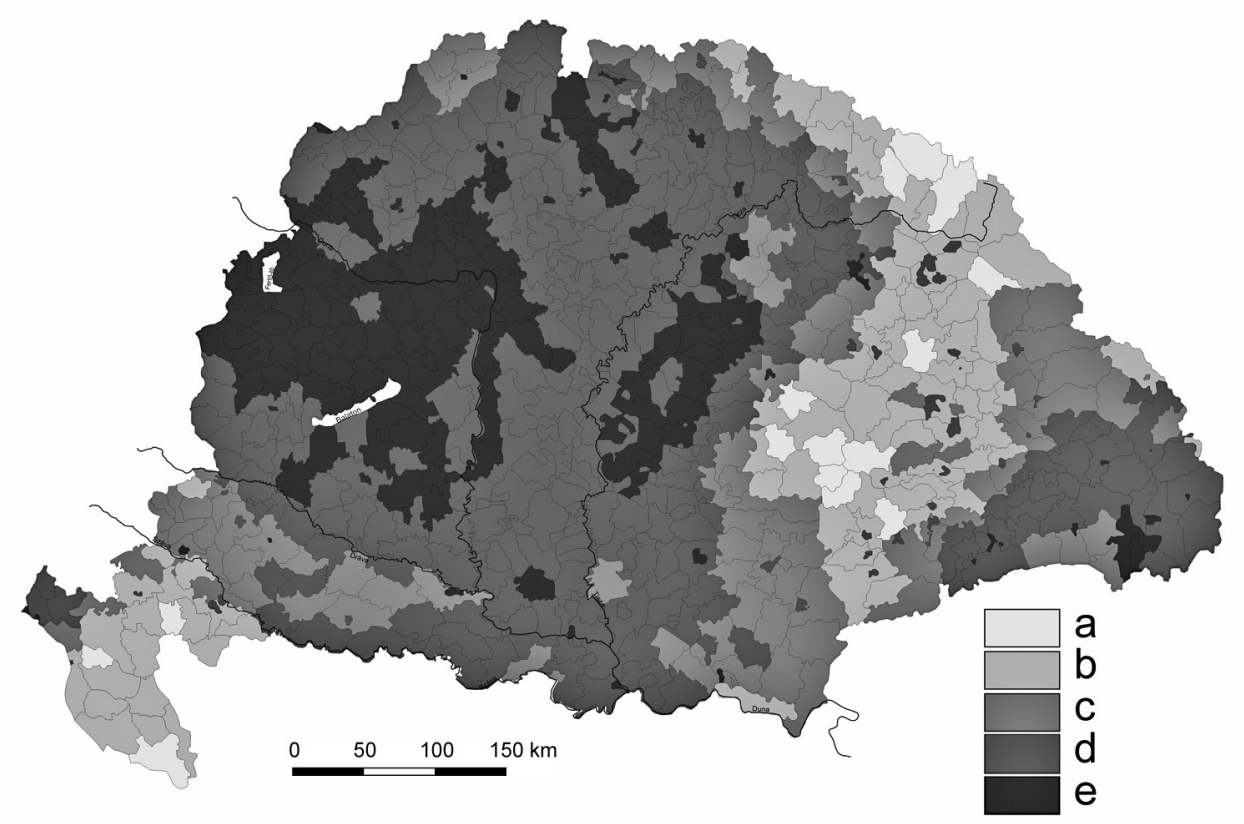

Zeichenerklärung: a: unter $20 \%$, b: $20-40 \%$, c: $40-60 \%$, d: $60-80 \%$, e: über $80 \%$

Abb. 1: Anteil der Personen, die lesen und schreiben können, in den Bezirken des historischen Ungarns, 1910 (Entwurf und Kartographie: Róbert GYŐRI)

\section{Entwicklungsunterschiede im historischen Westungarn zu Beginn des 20. Jahrhunderts}

Die Entwicklungsunterschiede im historischen Westungarn haben wir auf der Grundlage des von uns für das Jahr 1910 errechneten Entwicklungsindex in Abbildung 2 kartographisch dargestellt.

Es zeigt sich deutlich eine gut entwickelte Zone im Nordwesten und Westen der Region. Mit Sicherheit war sie der Nähe Wiens zuzuschreiben. Auf den Südwesten der Region wirkte sich - allerdings wesentlich weniger stark - der Einfluss von Graz aus. Er zeigte sich vor allem entlang der Eisenbahn und der Straße von Graz über Sankt Gotthard [Szentgotthárd] nach Körmend und nahe der steirischen Grenze. Außer diesen zwei größeren zusammenhängenden Zonen, die sich zweifellos westlich der Region Westungarn fortsetzten, fanden sich nur vereinzelt Gebiete mit überdurchschnittlichem Entwicklungsstand. Das Umland fast jeder Stadt bildete eine solche „Insel”. Daneben ragte noch die Umgebung von Devecser und Ajka hervor; dies wegen des wichtigen Weinbaugebiets von Somló und des Steinkohlenbergbaus von Ajka. 


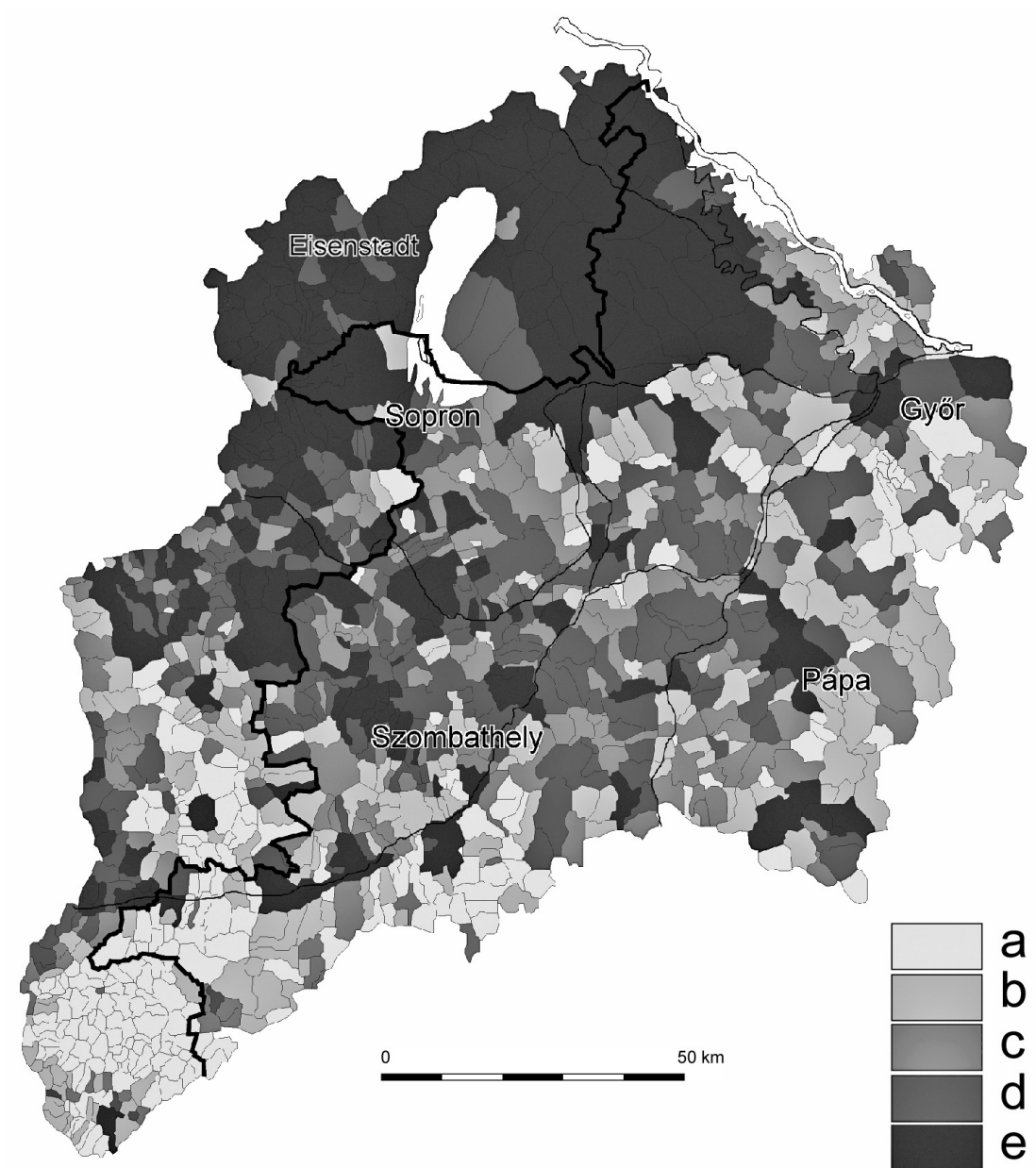

Zeichenerklärung: a: weit unter dem Durchschnitt, b: unter dem Durchschnitt, c: durchschnittlich, d: über dem Durchschnitt, e: weit über dem Durchschnitt

Abb. 2: Entwicklungsgrad der Siedlungen in Westungarn, 1910 (Entwurf und Kartographie: Róbert GYőRI)

Gebiete mit unterdurchschnittlichem Entwicklungsstand lagen an der Peripherie der Region. Dazu gehörten das marktfern gelegene, heute zu Slowenien gehörende Übermurgebiet [Prekmurje, ung. Vendvidék] mit seinen schlechten Bedingungen für die Landwirtschaft; der zwischen den Einzugsbereichen von Wien und Graz gelegene Bezirk Güssing; der südöstliche Teil des Komitats Eisenburg; und auch der Steinboden [Vasi-Hegyhát], der sich in Großgrundbesitz befand. Auf sie übten die städtischen Zentren kaum noch Einfluss aus. Nur um Körmend fanden sich noch vereinzelt besser situierte Siedlungen, in der Umgebung von Eisenburg [Vasvár] dagegen nicht mehr. Am Fuß des Bakonywaldes [Bakony], der sich von Pápa nach Süden und Osten er- 
streckt, vereinten sich ungünstige Bedingungen für die Landwirtschaft mit einer Lage an der Peripherie.

Nur schwer zu erklären ist die Situation im Komitat Raab. Raab [Győr], die größte Stadt in der ganzen Region, erscheint wie eine Insel in ihrem unterdurchschnittlich entwickelten Umland. Dem Durchschnitt der Region entsprachen nur Streifen entlang der Verkehrsachsen Raab - Wien und Raab - Pápa.

Zwischen den gut entwickelten Gebieten im Nordwesten und den Peripherien im Osten erstreckte sich eine breite Übergangszone. Sie war vor allem durch fortschrittliche Landwirtschaft und wohlhabende Dörfer gekennzeichnet, aber von den Zentren weit entfernt. Im landesweiten Vergleich würde sie zu den bestsituierten Gebieten gehört haben. Innerhalb der Region entsprach sie aber nur einem durchschnittlichen Entwicklungsniveau. Zu dieser Übergangszone gehörten zum Beispiel die Raabau [Rábaköz], das Kemenesalja oder der nordöstliche Teil des Komitats Eisenburg. Auch diese Übergangszone war einerseits von besser entwickelten Inseln und andererseits von „Depressionen” durchsetzt. Ein gutes Beispiel für den letzteren Fall war die Landschaft Cser an der Grenze der Komitate Ödenburg und Eisenburg.

\section{Auswirkungen der Grenze von Trianon auf den Einzugsbereich der Städte}

Fast jede der zahllosen Studien über den Friedensvertrag von Trianon (1920) beschäftigt sich mit den Auswirkungen der neuen Grenze auf die Regionalstruktur. Wie an anderen Grenzabschnitten versuchten auch an der neuen ungarischen Westgrenze die betroffenen Parteien ihre Gebietsansprüche zusätzlich mit wirtschaftlichen und wirtschaftsgeographischen Argumenten zu begründen. Letztlich war die Grenze aber das Resultat eines Kompromisses aus ethnischen, wirtschaftsräumlichen und strategischen Überlegungen. Das erklärt, warum - wie auch an anderen Grenzabschnitten - gut funktionierende Stadt-Umland-Beziehungen zerschlagen wurden, was die weitere Entwicklung nachteilig beeinflusste (KovÁcs 1990, S. 8-13).

An der neuen österreichisch-ungarischen Grenze blieben die wichtigeren Städte ohne Ausnahme bei Ungarn. Allerdings wurden sie vom größten Teil ihres Einzugsgebiets getrennt. Das wirkte sich auch sehr nachteilig auf die verkehrsgeographische Situation (vor allem des Burgenlandes) aus, denn mit den größeren Städten blieben auch die Bahnknoten bei Ungarn. Außer über die nun im Ausland gelegenen Städte Ödenburg und Steinamanger [Szombathely] waren das nördliche und das südliche Burgenland per Bahn jetzt nur noch über Niederösterreich und die Steiermark miteinander verbunden; das mittlere Burgenland hatte mit den beiden anderen Landesteilen überhaupt keine direkte Bahnverbindung mehr (BurghaRdT 1962, S. 197-200).7)

\footnotetext{
7) Paradoxerweise war die ungarische Revisionspolitik nach dem Ersten Weltkrieg gerade in Bezug auf diese aus ethnischer Sicht am wenigsten fragwürdige Grenze am aktivsten (und erfolgreichsten), was vor allem mit der wirtschaftlichen und politischen Schwäche des wie Ungarn als Kriegsverlierer geltenden Österreichs und des Burgenlandes zu erklären ist (HASLINGER 1996; BuRghaRdT 1962; Tóth 2006).
} 
Um diesen Problemkreis näher zu untersuchen, haben wir zunächst jene Siedlungen als Zentrale Orte eingestuft, die in dieser Region nach der Studie über die Städtehierarchie im Jahr 1910 von BELUSZKY und GYőRI (2005, S. 102-111) städtische Funktionen erfüllten (25 Siedlungen). Allerdings haben wir diese Liste noch um Städte erweitert, die außerhalb der Grenzen der Region und des Landes lagen, sowie um Mikrozentren, die in den sogenannten Verwaltungsinformationsblättern des Jahres 1925 als Markt und Zentraler Ort von zumindest fünf Gemeinden aufscheinen. Von den Zentren außerhalb der Region wurden auf ungarischem Gebiet jene berücksichtigt, die nach der genannten Studie der Städtehierarchie städtische Funktionen hatten; auf österreichischem Gebiet waren es die Verwaltungszentren in Grenznähe oder Siedlungen mit zumindest 2.000 Einwohnern.

Abbildung 3 zeigt als Ergebnis unserer Untersuchung die Einzugsbereiche dieser Zentralen Orte wie sie mit Hilfe des Gravitationsmodells ermittelt wurden (GYőRI 2006b). Es muss betont werden, dass die Modellrechnung nicht auf von Siedlung zu Siedlung verifizierbaren Daten beruht, sondern Verhältnismäßigkeiten und Tendenzen anzeigt.

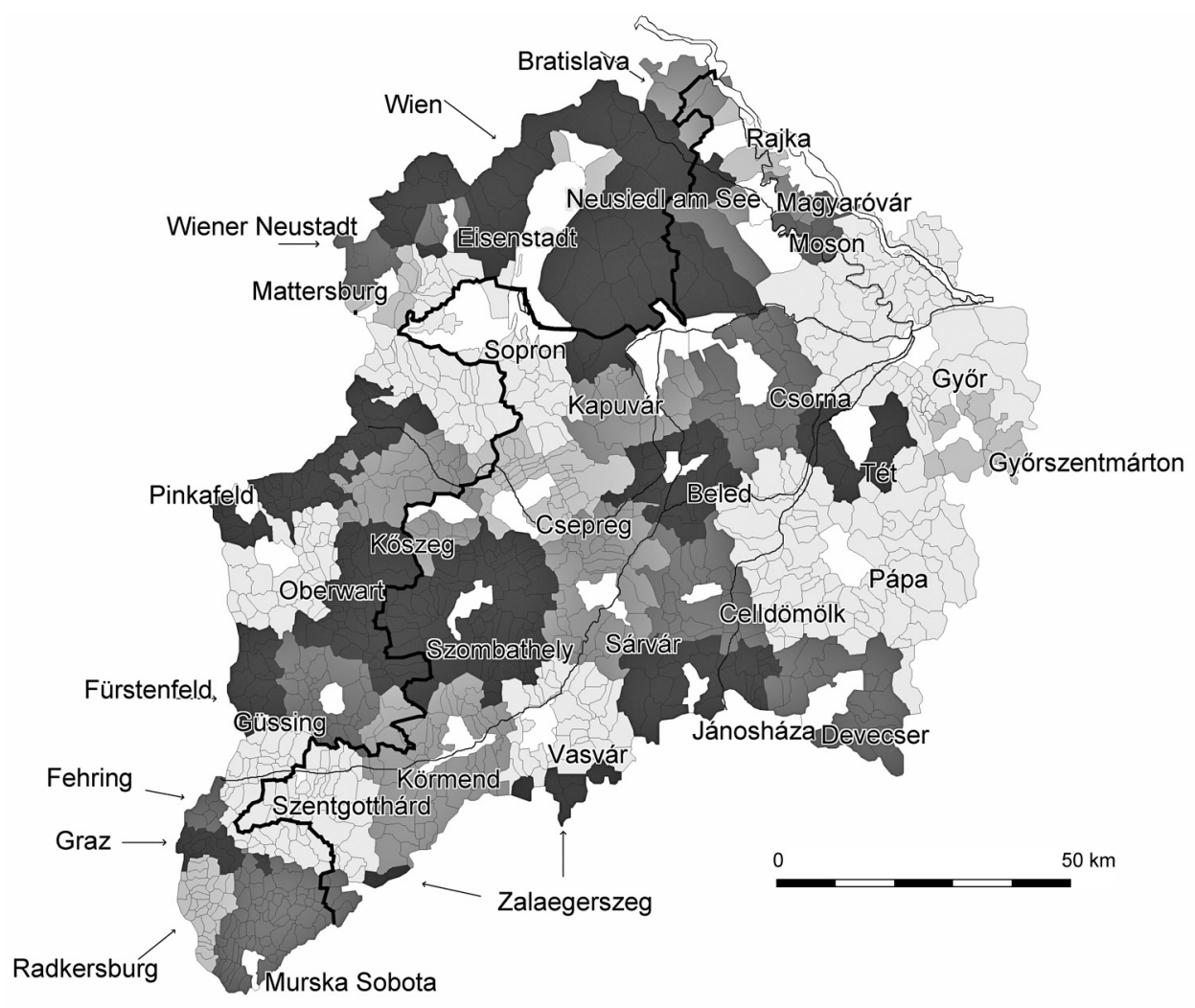

Abb. 3: Einzugsbereiche von Zentren in Westungarn, 1910 (Entwurf und Kartographie: Róbert GYŐRI). Die Grautöne markieren die Einzugsbereiche der einzelnen Zentren. 
Deutlich ist die bestimmende Rolle Wiens im nordwestlichen Teil der Region zu erkennen (GYŐRI 2006a). Wien verfügte auf dem Gebiet der untersuchten Region im Kleinen Ungarischen Tiefland [Kisalföld] und rechts der Donau über einen Einzugsbereich mit fast 90.000 Einwohnern (insgesamt 70 Gemeinden). Der starken Wirkung von Wien ist es zuzuschreiben, dass der Einzugsbereich von Pressburg [Bratislava], ungarisch Pozsony, kaum die Donau überschritt. Wien beeinträchtigte auch kleinere Zentren in den Komitaten Wieselburg und Ödenburg bei der Entfaltung einer eigenen Wirkung (Ragendorf [Rajka/Ragendorf], Wieselburg-Ungarisch-Altenburg [Mosonmagyaróvár/Wieselburg-Ungarisch-Altenburg]), was dort das Fehlen größerer Zentren erklärt. Selbst für den sehr eingeschränkten Einzugsbereich von Mattersburg (ung. Nagymarton) und die nicht so weite Ausdehnung des Einzugsbereich von Ödenburg nach Westen war Wien verantwortlich. Allerdings spielte dafür vor allem hinsichtlich Mattersburgs auch die Nähe von Wiener Neustadt eine Rolle.

Etwas anders stellte sich die Situation im östlichen und südlichen Teil des Komitats Eisenburg dar. Hier reichte der Einzugsbereich der steirischen Städte - nicht trotz vieler potenzieller Zentren, sondern aus Mangel daran - über die alte ungarische Grenze hinaus. So wirkte nicht nur Graz in das alte Ungarn (zum Großteil in das spätere Burgenland) hinein. Auch das Hinterland von Radkersburg und Fürstenfeld dehnte sich über die alte Grenze aus. Sogar der kleine Bezirkshauptort Fehring verfügte über ein sechs Dörfer umfassendes Hinterland auf bis 1920 ungarischem Gebiet. Das bestätigt, dass das im heutigen Slowenien gelegene Murska Sobota (ung. Muraszombat) und Sankt Gotthard im Verhältnis zu ihrer zentralörtlichen Bedeutung über einen zu großen Verwaltungsbezirk verfügten.

Die neue Staatsgrenze betraf mit Ausnahme von Pápa den Einzugsbereich sämtlicher bedeutender Zentren. Vom Einzugsbereich Wiens innerhalb der untersuchten Region verblieben etwa $15 \%$ auf der ungarischen Seite der Grenze. Den vergleichsweise größten Verlust erlitt Güns [Kőszeg]: von den etwa 20.000 Einwohnern seines Einzugsbereiches gerieten mehr als drei Viertel auf die andere Seite der Grenze, in Ungarn verblieben insgesamt elf Gemeinden. In der Reihe der „Verlierer” folgt Ödenburg. Es behielt weniger als $40 \%$ seines vormaligen Hinterlandes. Steinamanger dagegen konnte $63 \%$ seines früheren Einzugsbereichs behalten. Der Einzugsbereich von Sankt Gotthard wurde unter drei Staaten aufgeteilt. Fast gleich große Teile kamen zu Österreich und Ungarn, das Königreich der Serben, Kroaten und Slowenen, das spätere Jugoslawien, erhielt ein Sechstel des früheren Einzugsbereichs von Sankt Gotthard.

Ein relativer "Gewinner“ der neuen Grenzziehung war Wieselburg-UngarischAltenburg. Diese Doppelstadt konnte durch die neuen Grenzen sowohl der Konkurrenz von Wien als auch von Pressburg entkommen. Auch der Einfluss der kleineren burgenländischen Zentren wuchs. Eisenstadt (ung. Kismarton), Mattersburg, Oberpullendorf/ Felsőpulya, Oberwart/Felsőőr, Pinkafeld (ung. Pinkafő), Güssing (ung. Németújvár) verloren ihre ungarischen Konkurrenten. Manche Orte wuchsen auch ohne Verlust eines früheren Konkurrenten in zentrale Funktionen hinein; so zum Beispiel das südburgenländische Jennersdorf (ung. Gyanafalva).

Einen gewissen Bedeutungszuwachs erfuhren infolge der neuen Grenze auch einige Städte in Niederösterreich und in der Steiermark wie Wiener Neustadt, Fürstenfeld, Fehring (Burghardt 1962, S. 235-237; SEger et al. 1993, S. 64). 


\section{Entwicklung der Regionalstruktur vom Ersten Weltkrieg bis in die 1970er Jahre}

Die soeben beschriebene Struktur bildete also den Ausgangspunkt für die unterschiedliche Regionalentwicklung, die nach dem Ersten Weltkrieg beiderseits der neuen Grenze einsetzte. Als wesentliche Faktoren wirkten sofort die neuen Einzugsbereiche und der Verlust der richtungsweisenden Rolle Wiens im ungarisch gebliebenen Teil der Region. Dagegen machten sich makroökonomische Einflüsse erst nach der Errichtung des Eisernen Vorhangs deutlich differenzierend bemerkbar.

Das Auseinanderdriften der beiden Grenzgebiete erweist sich auch in der Bevölkerungsentwicklung. Dies zeigt Abbildung 4, in der Phasen des jeweiligen Bevölkerungshöchststandes in einer Verwaltungseinheit im Zeitraum zwischen 1870 bis 2001 angegeben sind.

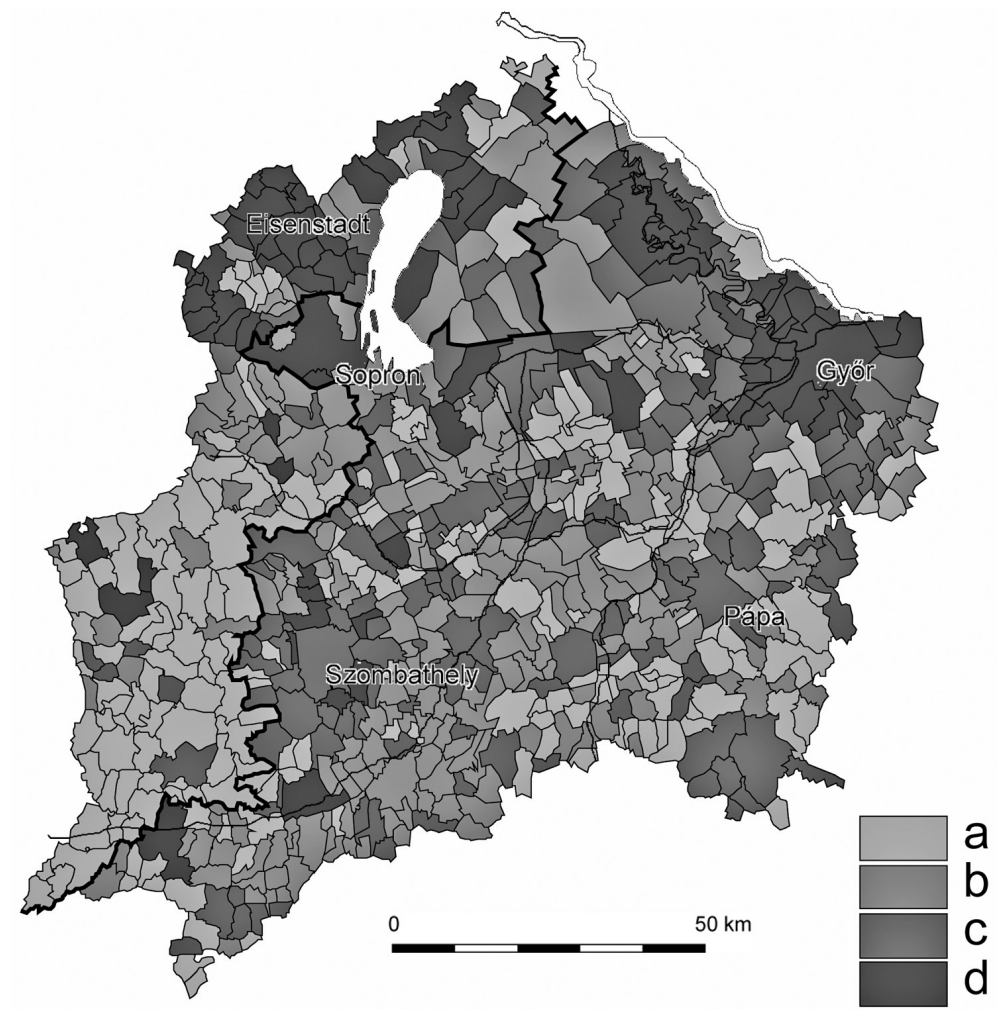

Zeichenerklärung (im Fall von zwei Jahreszahlen: Ungarn/Österreich): a: 1870-1910, b: 1920/23 -1941/39, c: 1950/51-1990/91, d: 2001

Abb. 4: Bevölkerungsmaxima von Gemeinden im Untersuchungsgebiet zwischen 1870 und 2001 (Entwurf und Kartographie: Ferenc JANKó) 
Demnach erreichte die südliche Hälfte des Burgenlandes um die Jahrhundertwende den Einwohnerhöchststand. Die Bezirksstadt Jennersdorf zum Beispiel hatte im Jahr 1890 um ca. 1.000 Einwohner mehr als zur Volkszählung des Jahres 2001. Ein Grund dafür ist wohl die Siedlungsstruktur des südlichen Burgenlandes. Mit seinen kleinen Dörfern konnte es bei sinkendem Arbeitskräftebedarf in der Landwirtschaft schon ab der Jahrhundertwende und angesichts eines nicht ausreichenden Arbeitsplatzangebots in den ländlichen Zentren seine Bevölkerung nicht halten. Arbeitssuchende waren gezwungen abzuwandern. Viele von ihnen wanderten aus, auch noch in der Zwischenkriegszeit (KIRNBAUER 1977, S. 132-135).

Auch auf der ungarischen Seite der Grenze zeigen größere Gebiete ähnliche Charakteristika, vor allem die südliche Hälfte der Raabau und in der Ebene von Pápa die von den Zentren entfernter liegenden Gemeinden. Im Gegensatz zum Südburgenland erreichte der größte Teil von Westtransdanubien aber erst zwischen den beiden Weltkriegen oder in der kommunistischen Periode sein Bevölkerungsmaximum. In der Umgebung von Raab, Wieselburg-Ungarisch-Altenburg und Ödenburg erreichte die Bevölkerungszahl dagegen wie im nördlichen Burgenland erst bei der Volkszählung 2001 ihren Höchststand.

Zwischen den beiden Weltkriegen diversifizierten sich die Entwicklungen zu beiden Seiten der Grenze noch nicht sehr. Allerdings verloren im Burgenland fast alle kleineren Gemeinden an Einwohnern und fiel die südliche Hälfte immer weiter zurück, während der ungarische Grenzraum relativ stabil blieb. Das hatte damit zu tun, dass auf österreichischer Seite größere Zentrale Orte fehlten und ein neues zentralörtliches System erst aufgebaut werden musste, während auf ungarischer Seite immerhin die Zentren verblieben waren. Zwar war auch dort das Eisenbahnnetz nicht sehr hilfreich, doch wurde es durch regen Autobusverkehr ersetzt (KNABL 1977, S. 23-24; SEGER et al. 1993).

Nach dem Zweiten Weltkrieg war zu beiden Seiten der Grenze die Entagrarisierung der markanteste sozio-ökonomische Prozess. Noch kurz nach dem Zweiten Weltkrieg war im Burgenland der Anteil der in der Landwirtschaft Erwerbstätigen an der Gesamtzahl der Erwerbstätigen wesentlich höher als in den ungarischen Grenzkomitaten. Doch „unterbot“ das Burgenland bereits zur Zeit der Volkszählungen 1970/71 den Durchschnittswert der Komitate Raab-Ödenburg [Győr-Sopron megye] und Eisenburg [Vas megye] (vgl. Tab. 2). Der Prozess schritt also auf österreichischer Seite viel schneller voran. Zur Zeit der politischen Wende in Ungarn (1990/91) war der Anteil im Burgenland nur noch halb so groß wie in den ungarischen Komitaten und näherte sich dem westeuropäischen Durchschnitt an (SEger et al. 1993, S. 50-53; vgl. Penz 1997). Die industrielle Entwicklung schritt in der ganzen Region nur sehr langsam voran.

Dies gilt auch für das Burgenland. Bis zum Zweiten Weltkrieg gab es in Eisenstadt keinen bedeutenderen Industriebetrieb, und im ganzen Land hatten nur die Zuckerfabriken in Hirm (ung. Félszerfalva) und Siegendorf/Cindrof (ung. Cinfalva) sowie die Textilbetriebe in Pinkafeld, Neufeld an der Leitha (ung. Lajtaújfalu) und Neudörfl an der Leitha (ung. Lajtaszentmiklós) eine über die unmittelbare Umgebung hinausreichende Wirkung.

Wesentlich behindert wurde die Entwicklung auch noch nach dem Zweiten Weltkrieg durch die sowjetische Besatzung bis 1955. Das Burgenland erhielt kaum Hilfe aus dem Marshall-Plan, und Investoren mieden es lange. Noch in den 1960er Jahren war 


\begin{tabular}{|l|c|c|c|c|c|c|}
\hline & $\mathbf{1 9 4 9 / 5 1}$ & $\mathbf{1 9 6 0 / 6 1}$ & $\mathbf{1 9 7 0 / 7 1}$ & $\mathbf{1 9 8 0 / 8 1}$ & $\mathbf{1 9 9 0 / 9 1}$ & $\mathbf{2 0 0 1}$ \\
\hline Burgenland & 63,1 & 48,4 & 26,6 & 14,3 & 8,2 & 4,8 \\
\hline $\begin{array}{l}\text { Komitat Raab(-Wieselburg)- } \\
\text { Ödenburg [Győr(-Moson)- } \\
\text { Sopron megye] }\end{array}$ & 49,7 & 34,2 & 25,3 & 18,0 & 14,8 & 5,8 \\
\hline $\begin{array}{l}\text { Komitat Eisenburg [Vas } \\
\text { megye] }\end{array}$ & 54,1 & 45,7 & 31,4 & 19,7 & 18,4 & 5,6 \\
\hline
\end{tabular}

Quellen: KSH 1950a, 1962a, 1962b, 1971a, 1971b, 1981a, 1981b, 1992a, 1992b, 2002a, 2002b; ÖSTAT 1952a, 1963a, 1972, 1985, 1995; SA 2002b

Tab. 2: Entagrarisierung im Untersuchungsraum. Anteil der Erwerbstätigen in der Landwirtschaft, 1949/51-2001

die Textilindustrie der größte Arbeitgeber, obwohl sich auch Metall-, Maschinenbauund Elektroindustrie niedergelassen hatte. Die Zahl der Industriearbeiter überschritt erst Mitte der 1960er Jahre die Zahl der in der Landwirtschaft Erwerbstätigen. Auch dies war aber weniger der ortsansässigen Industrie, als dem verstärkten Pendeln zu Industriearbeitsplätzen in Wien und Niederösterreich zu verdanken, das durch StraBenbau und Motorisierung ermöglicht und erleichtert wurde. Die Volkszählung des Jahres 1961 erfasste im Burgenland insgesamt 37.000 Pendler. Davon arbeiteten 24.000 außerhalb der Grenzen des Bundeslandes. Von diesen 24.000 pendelten 14.000 nach Wien, 7.000 nach Niederösterreich und nur 2.200 in die Steiermark (KNABL 1977, S. 27-28; Titz 1977, S. 70).

In den ungarischen Grenzkomitaten wurde die Industrialisierung zunächst aus politischen Gründen, wegen der grenznahen Lage, zurückgehalten. Bis in die 1960er Jahre machte sich ein deutlicherer Industrialisierungsprozess nur in der Umgebung von Raab bemerkbar. Ihm ist es zu verdanken, dass im Komitat Raab-Ödenburg ähnlich wie im Burgenland der Anteil der Industriebeschäftigten bei 35\% lag, während er im Komitat Eisenburg nur 24\% erreichte.

Eine stark hemmende Wirkung hatte auf ungarischer Seite die schlechte Infrastruktur. Dem standen im Burgenland große Fortschritte gegenüber. Dies galt auch für die Modernisierung des Wohnraumes (vgl. Tab. 3). Beides führte schon in den 1960er Jahren zu einem deutlichen Unterschied im Lebensniveau (Lichtenberger 2002, S. 262). ${ }^{8)}$

Abbildung 5 mit den Daten des zweiten Entwicklungsindex (1960/61) lässt gut erkennen, dass sich das südliche Burgenland dem Norden angenähert hat. Im gesamten Bundesland finden sich kaum noch Gemeinden, die unter dem Durchschnitt liegen. Obwohl das Nord-Süd-Gefälle noch deutlich ist, wird es schon von einem WestOst-Gefälle (über die Grenze hinweg) dominiert. Letzteres wird verstärkt durch den Verfall der Raabau, des Tals der Rabnitz [Répce, Rábca] und der Ebene von Pápa. Die Gemeinden dieser Gebiete gerieten größtenteils in die Kategorien „,unterdurchschnittlich“ oder „durchschnittlich“, wobei das Gebiet des Steinbodens [Vasi-Hegyhát] zum

\footnotetext{
8) Der Anteil der an das Leitungswasser angeschlossenen Wohnungen überschritt in den Gemeinden des Ko-
} mitats Raab-Ödenburg 1980, in denen des Komitats Eisenburg erst zur Volkszählung 1990 die 50\%-Marke. 
Regionalentwicklung im Burgenland und in Westungarn während des 20. Jahrhunderts 231

\begin{tabular}{|l|c|c|c|c|c|c|}
\hline & $\mathbf{1 9 4 9 / 5 1}$ & $\mathbf{1 9 6 0 / 6 1}$ & $\mathbf{1 9 7 0 / 7 1}$ & $\mathbf{1 9 8 0 / 8 1}$ & $\mathbf{1 9 9 0 / 9 1}$ & $\mathbf{2 0 0 1}$ \\
\hline Burgenland & 43,9 & 23,3 & 12,6 & 7,7 & 5,1 & 1,0 \\
\hline $\begin{array}{l}\text { Komitat Raab(-Wieselburg)- } \\
\text { Ödenburg [Győr(-Moson)- } \\
\text { Sopron megye] }\end{array}$ & 66,0 & 56,9 & 37,8 & 20,3 & 12,5 & 9,3 \\
\hline $\begin{array}{l}\text { Komitat Eisenburg [Vas } \\
\text { megye] }\end{array}$ & 70,5 & 62,9 & 44,6 & 26,0 & 16,0 & 11,5 \\
\hline
\end{tabular}

Quellen:KSH 1950b, 1962d, 1971a, 1971b, 1981a, 1981b, 1992a, 1992b, 2002a, 2002b; ÖSTAT 1952b, 1963b, 1973, 1982, 1992; SA 2004

Tab. 3: Anteil der bewohnten Wohnungen mit einem Wohnraum, 1949/51-2001

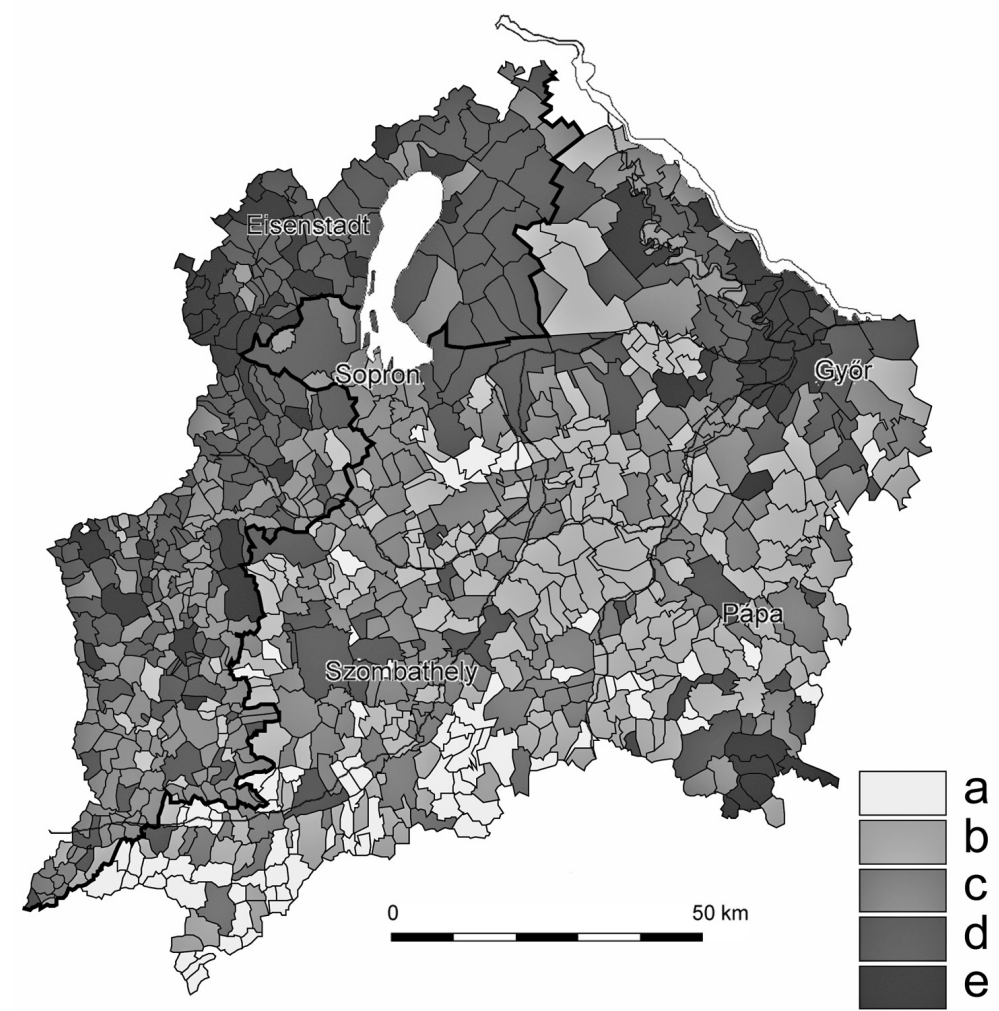

Zeichenerklärung: a: weit unter dem Durchschnitt, b: unter dem Durchschnitt, c: durchschnittlich, d: über dem Durchschnitt, e: weit über dem Durchschnitt

Abb. 5: Entwicklungsgrad von Gemeinden im Burgenland und in Westtransdanubien, 1960/61 (Entwurf und Kartographie: Ferenc JANKó) 
größten Teil ohnehin schon tief unter dem Durchschnitt lag. Es hatte also der Verfall der Gebiete zwischen den größeren Städten Ödenburg, Raab, Steinamanger, Pápa und Ajka und damit eine Polarisierung zu Lasten des ländlichen Raumes begonnen.

Die Umgebung der größeren Zentren wurde hingegen urbanisiert. Das ist am besten in der Umgebung von Raab zu erkennen, wo das im Jahr 1910 auffällige Entwicklungsvakuum im Süden der Stadt im Jahr 1960 nicht mehr existiert. Besonders deutlich ist auch der Fortschritt entlang der Verkehrsachsen.

\section{Die Regionalentwicklung von den 1970er Jahren bis heute}

In den 1970er Jahren setzte in Ungarn eine Liberalisierung des politischen und wirtschaftlichen Systems ein. Der Ausbau der Infrastruktur, die beginnende Eigenständigkeit von Unternehmen, die behutsame Einführung von Marktmechanismen und politisches Tauwetter führten zu einer Stärkung des Dienstleistungssektors, verbesserten die Versorgungslage der Bevölkerung und kurbelten den Tourismus an. Dennoch schrumpfte die Bevölkerungszahl der meisten Gemeinden. Vor allem das Tal der Rabnitz und der Steinboden erlitten eine Bevölkerungserosion beachtlichen Ausmaßes.

Im Burgenland verbesserten sich weiterhin die Möglichkeiten des Tagespendelns. Dennoch konnte dadurch der Bevölkerungsrückgang in den ländlichen Gebieten nicht völlig aufgehalten werden. Größere Bevölkerungsverluste gab es aber nur noch im mittleren Burgenland und im südburgenländischen Pinkatal entlang der Grenze zu Ungarn (SEGER et al. 1993, S. 57-63).

In den 1970er Jahren erhielt das Burgenland verstärkt Bundesförderung. Der dadurch mögliche Ausbau der Infrastruktur wirkte sich positiv auf Investitionen aus, es wurde viel in Elektronikindustrie, Metall- und Textilindustrie investiert, also vor allem in Industriezweige, die das Land bisher nicht geprägt hatten (TiTz 1977, S. 83-91; EcKhardt 1980; Trummer 1995, S. 25-29). ${ }^{9)}$ Jedoch konnten damit weder die Abwanderung, noch das Pendeln verringert werden. Die Zahl der Pendler wuchs im Gegenteil auf 63.000 im Jahr 1981 an. Die Hälfte von ihnen arbeitete außerhalb des Bundeslandes. Bei der Volkszählung des Jahres 2001 wurden sogar 87.500 Pendler gezählt (davon 41.600 nach außerhalb des Bundeslandes). Das bedeutete, dass mehr als zwei Drittel der burgenländischen Arbeitnehmer pendelten (WINDISCH 1991, S. 54-55).

Diese Entwicklung hat den kleinen burgenländischen Städten relativ große Bedeutung für den Arbeitsmarkt verschafft. So pendelten im Jahr $2001 \mathrm{mehr}$ als doppelt so viele Berufstätige (mehr als 10.000) nach Eisenstadt wie nach Ödenburg, obwohl Ödenburg das Fünffache an Einwohnern hat. In Eisenstadt kam die Zahl der Einpendler sogar der Zahl der Einwohner gleich.

Durch das politische Tauwetter der 1970er Jahre belebten sich die grenzüberschreitenden wirtschaftlichen Kontakte wieder, zunächst vor allem im Tourismus und Ein-

\footnotetext{
9) Auch das technologische Niveau dieser Betriebe war wesentlich höher als in Ungarn.
} 
kaufstourismus. Sie bildeten die Basis für eine schlagartige Ausweitung österreichischer wirtschaftlicher Aktivitäten in Ungarn nach der politischen Wende. Wie schon hundert Jahre zuvor übernahm österreichisches Kapital durch die Privatisierung bestehender Firmen oder die Gründung neuer Unternehmen eine wichtige Rolle bei der Modernisierung der Wirtschaft im ungarischen Teil der Region, wobei in Kauf genommen wurde, dass dadurch in einigen Fällen Arbeitsplätze im Burgenland oder in anderen Teilen Österreichs verloren gingen. In der Region etablierte sich Einkaufstourismus in beide Richtungen. Er trug dazu bei, die Einzugsgebiete der grenznahen ungarischen Städte fast wieder auf ihre ursprüngliche Größe auszuweiten (MichaLKó 2004, S. 28 , S. 70-76). Die wirtschaftlichen Kontakte belebten sich außerdem durch viele Ungarn, die in Österreich arbeiten. Diesem Zustrom steht die österreichische Seite aber mit Vorbehalten gegenüber, und man ist vorerst bestrebt, ihn durch eine Quotenregelung und sehr strenge Kontrollen im Rahmen zu halten (HARDi 2005; POLSTERER 2002).

Obwohl das Burgenland in Österreich auch heute noch als eine weniger gut entwickelte Region gilt, gelangen ihm nach dem Beitritt Österreichs zur Europäischen Union (EU) im Jahr 1995 durch die Ziel-1-Förderung der EU spektakuläre Erfolge. Dies, obwohl die Grenzöffnung auch den Verlust an Arbeitsplätzen mit sich brachte. So wanderten etliche Textilbetriebe nach Osten ab. ${ }^{10)}$ Der Einkaufstourismus aus der ungarischen Nachbarschaft und der Zustrom relativ billiger Arbeitskräfte konnten diese negativen Effekte aber doch großteils kompensieren. Heute unterscheidet sich das Burgenland bezogen auf das Bruttoinlandsprodukt pro Kopf der Bevölkerung nach Kaufkraftparitäten nicht mehr wesentlich vom Durchschnitt der EU.

Die ungarische Grenzregion hingegen liegt an diesem Maßstab gemessen unter 75\% des Durchschnitts der 27 Mitgliedstaaten der EU, wobei das Komitat Raab-WieselburgÖdenburg [Győr-Moson-Sopron megye] in den letzten Jahren bessere Werte als das Südburgenland erreichte. Ohne Berücksichtigung von Kaufkraftparitäten indiziert das Bruttoinlandsprodukt pro Kopf jedoch nach wie vor unterschiedliche Produktivität und ein sehr unterschiedliches Niveau der Wertschöpfung im Burgenland und in Westtransdanubien im Verhältnis $95 \% \mathrm{zu} 40 \%$ (Eurostat - http://epp.eurostat.ec.europa.eu).

Im Burgenland ist auch der Tertiärisierungsprozess weiter fortgeschritten. Der Anteil der in der Industrie oder in der Landwirtschaft Erwerbstätigen erreicht nur in einzelnen Industrie- oder Agrargemeinden einen höheren Wert.

Auch in Bezug auf die Infrastruktur zeigen sich noch große Unterschiede. Während es im Burgenland kaum noch Wohnungen mit weniger als vier Zimmern gibt, häufen sich in Westungarn die Gemeinden, in denen noch ein Fünftel der Wohnungen nur ein Zimmer haben. Das Niveau des Burgenlandes wird dort nur in den größeren Städten und in suburbanen Zonen erreicht.

So zeigt sich in Abbildung 6, welche den dritten Entwicklungsindex für das Jahr 2001 darstellt, ein deutliches West-Ost-Gefälle. Im Burgenland erweisen sich nur noch wenige Gemeinden als nur durchschnittlich entwickelt. In Westungarn hingegen liegen die südliche Hälfte der Raabau, das Kemenesalja, die Ebene von Pápa und die Umgebung von Eisenburg im Gebiet des Steinbodens weit unter dem Durchschnitt.

\footnotetext{
10) Auch in Westtransdanubien brach das frühere „Textilfünfeck“ Raab, Wieselburg-Ungarisch-Altenburg, Ödenburg, Steinamanger, Pápa zusammen.
} 


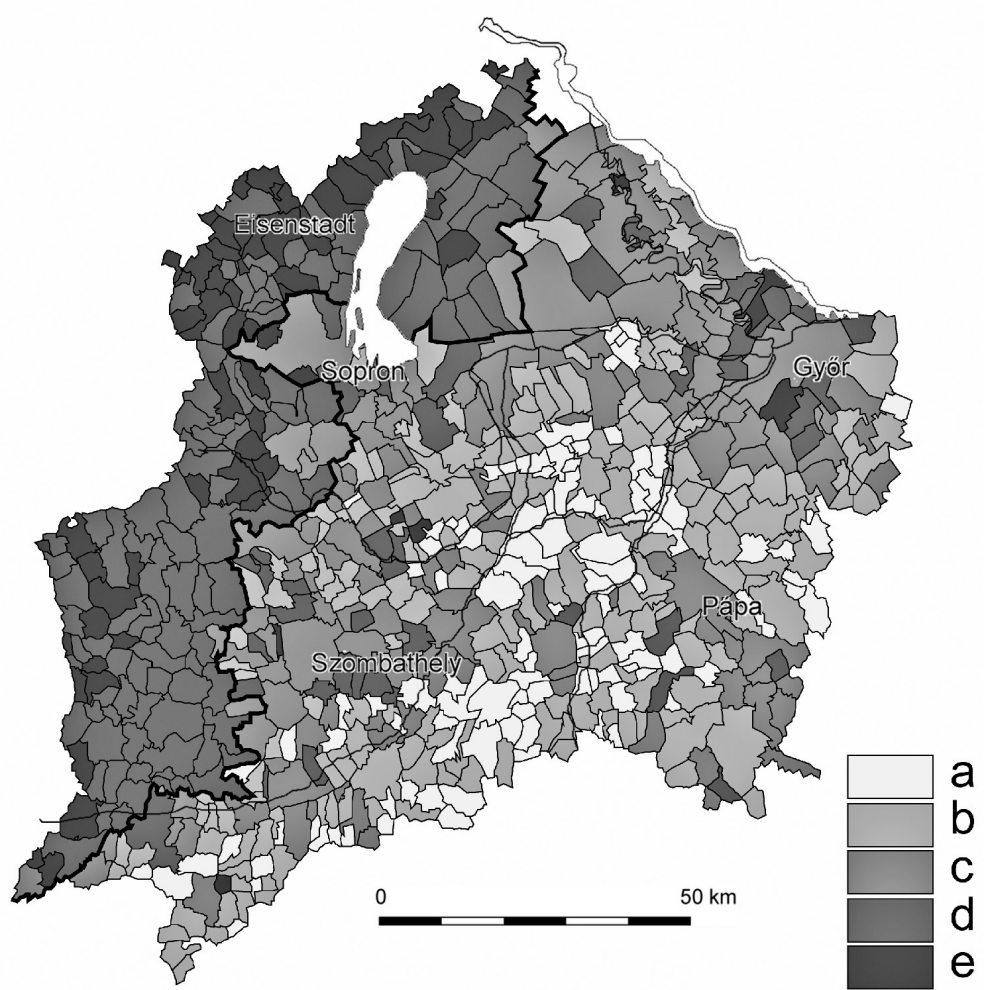

Zeichenerklärung: a: weit unter dem Durchschnitt, b: unter dem Durchschnitt, c: durchschnittlich, d: über dem Durchschnitt, e: weit über dem Durchschnitt

Abb. 6: Entwicklungsgrad von Gemeinden im Burgenland und in Westtransdanubien, 2001 (Entwurf und Kartographie: Ferenc JANKó)

Außerdem sind zumindest relative Positionsverluste der ungarischen Städte zu verzeichnen, darunter besonders jener von Ajka mit seinem Bergbau und seiner Industrie. Erwähnenswert ist aber auch, dass sich die südliche Hälfte des Steinbodens und der ungarische Teil des ansonsten in Slowenien liegenden Übermurgebiets [Vendvidék] aus der Kategorie „,weit unter dem Durchschnitt“ in die Kategorien „unter dem Durchschnitt“ bzw. ,durchschnittlich“ verbesserten.

Weniger deutlich als das West-Ost-Gefälle, aber doch, zeigt sich auch im Jahr 2001 weiterhin in der ganzen Region ein Nord-Süd-Gefälle. Es ist im Burgenland wesentlich durch den Einfluss des Wiener Zentralraums auf das Nord- und Mittelburgenland bedingt, während das Südburgenland von diesem Einfluss nur noch sehr teilweise erreicht wird. Auf ungarischem Gebiet zeigt sich vor allem die belebende Wirkung der Verkehrs- und Wirtschaftsachse Budapest - Raab - Wien auf den Norden des Komitats Raab-Wieselburg-Ödenburg.

Diese Einflüsse führten dazu, dass auch noch bis zum Jahr 2001 in beiden Teilgebieten der Bevölkerungsschwerpunkt weiter nach Norden gewandert ist (vgl. Abb. 7). 


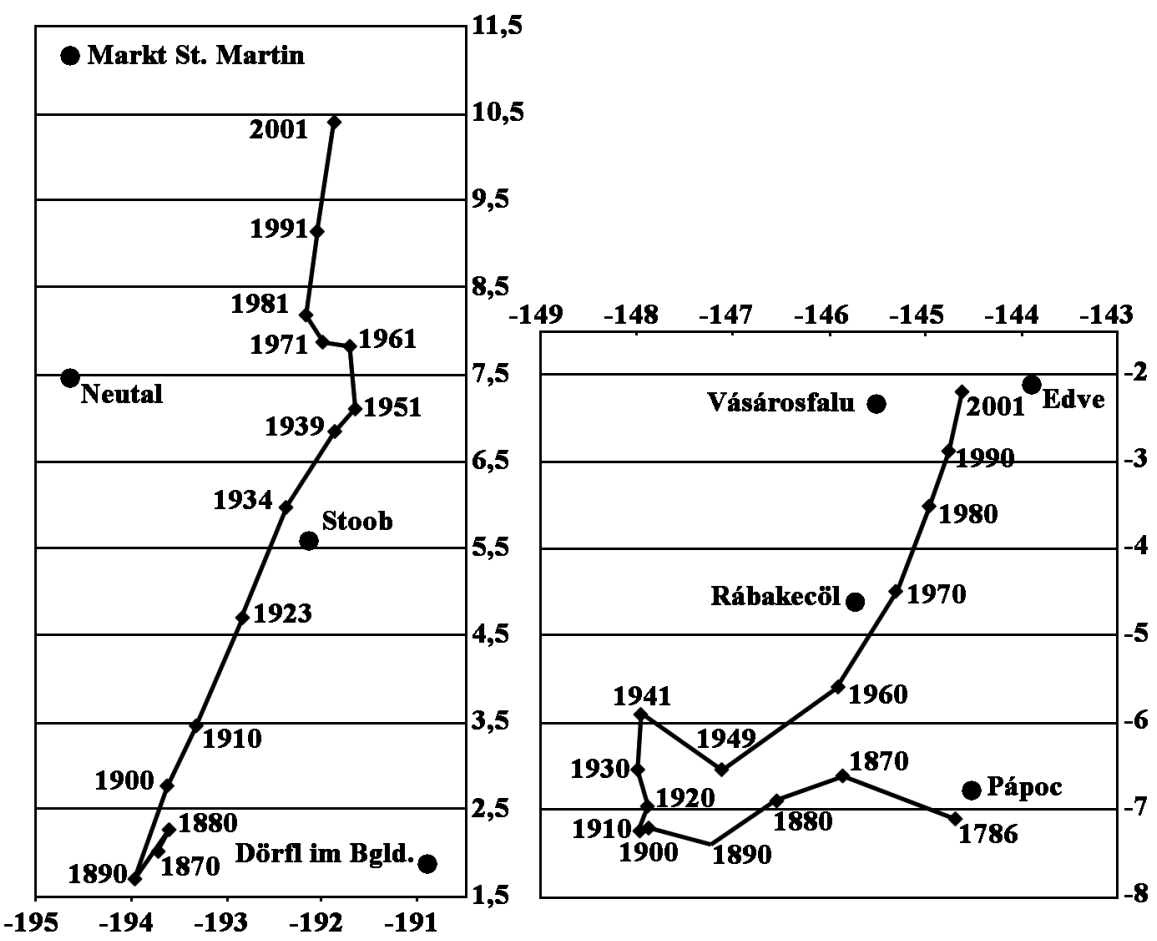

Abb. 7: Verlagerung des Bevölkerungsschwerpunktes im Burgenland und in Westtransdanubien, 1786-2001 (Entwurf und Kartographie: Róbert GYőRI)

\section{Schluss}

Schon nach der politischen Wende des Jahres 1989 und noch mehr nach dem EU-Beitritt Ungarns im Jahr 2004 fiel für Westtransdanubien das jahrzehntelange Hindernis der Westgrenze. Damit erlangte es innerhalb weniger Jahre wieder eine führende Stellung unter den ungarischen Regionen.

Es handelt sich dabei um die Wiederherstellung der Situation vor dem Zweiten Weltkrieg. Es sind im Wesentlichen auch die damals schon wirksamen Faktoren dafür maßgebend: die Stellung Westtransdanubiens als Ungarns Tor zum Westen, seine Vorteile innerhalb Ungarns in Bezug auf Infrastruktur, Bildungsstand der Bevölkerung und Arbeitskultur.

Vor diesem Hintergrund erscheint die Phase des Kommunismus nur als ein Intermezzo. Sie reichte aber doch aus, um Westtransdanubien gegenüber dem Burgenland nicht nur einen bedeutenden Modernisierungsrückstand zuzufügen, sondern auch seine innere räumliche Polarisierung zu akzentuieren, so dass diese heute stärker als im Burgenland ist. 
Abgesehen von makroökonomischen Einflüssen kann wahrscheinlich eine möglichst intensive Annäherung an das alte und neue Zentrum Wien am ehesten bewirken, dass dieser Rückstand wieder aufgeholt wird.

\section{Literaturverzeichnis}

Beluszky P. (2000), Egy félsiker hét stációja (avagy a modernizáció regionális különbségei a századelő Magyarországán) [Sieben Stationen eines Halberfolges - regionale Unterschiede der Modernisierung in Ungarn am Anfang des 20. Jhts.]. In: DövÉNYI Z. (Hrsg.), Alföld és Nagyvilág. Tanulmányok Tóth Józsefnek, S. 299-326. Budapest, MTA FKI.

Beluszky P. (2005), Magyarország ipara a századelőn [Ungarns Industrie am Beginn des Jahrhunderts]. In: Beluszky P. (Hrsg.), Magyarország történeti földrajza. (I. kötet.), S. 396-443. Budapest - Pécs.

BeluszKy P., GyőRI R. (2005), Magyar városhálózat a 20. század elején [Das ungarische Städtenetz zu Beginn des 20. Jahrhunderts]. Budapest - Pécs, Dialóg-Campus Kiadó.

Blotevogel H.H. (1996), Aufgaben und Probleme der Regionalen Geographie heute. In: Berichte z. dt. Landeskunde, 70, 1, S. 11-40.

Bohle H.-G. (2007), Geographische Entwicklungsforschung. In: Gebhardt H., Glaser R., RadtKe U., Reuber P. (Hrsg.), Geographie. Physische Geographie und Humangeographie, S. 796-815. Heidelberg, Spektrum Akad. Verlag.

BRUGGER E.A. (1984), Regionalforschung aus humangeographischer Sicht: Ein Programmvorschlag. In: Mitt. d. Österr. Geogr. Ges., 126, S. 68-84.

Burghardt A.F. (1962), Borderland. A historical and geographical study of Burgenland, Austria. Madison, Univ. of Wisconsin.

Chari S. (2009), Development. In: Derek G., Johnston R., Pratt M.J., Whatmore S. (Hrsg.), The Dictionary of Human Geography, 5. Aufl., S. 155-156. Chichester, Wiley-Blackwell.

Corbridge S. (2009), Post-development. In: Derek G., Johnston R., Pratt M.J., Whatmore S. (Hrsg.), The Dictionary of Human Geography, 5. Aufl., S. 562-564. Chichester, WileyBlackwell.

EcKhardt W. (1980), Grenzlandprobleme des Burgenlandes. In: Klose A., Lange A. (Hrsg.), Gemeinde im Grenzland, S. 95-104, Wien, Österr. Wirtschaftsverlag.

Ezcurra R., Rapún M. (2006), Regional disparities and national development revisited. The case of Western Europe. In: European Urban and Regional Studies, 13, 4, S. 355-369.

Good D. F (1993), The Economic Lag of Central and Eastern Europe: Evidence from the Late Nineteenth-Century Habsburg Empire. Univ. of Minnesota Working Paper 1993-7. http://www.cas.umn.edu/pdf/wp937.pdf [Abruf: 01.07.2009.]

GYŐRI R. (2005), A térszerkezet átalakulásának elemei a Kisalföld déli részén (a XVIII. század végétôl a XX. század elejéig) [Aspekte des Wandels der Regionalstruktur im südlichen Teil des Kleinen Ungarischen Tieflandes (vom Ende des 18. Jahrhunderts bis zum Beginn des 20. Jahrhunderts)]. PhD értekezés, kézirat, Budapest.

GYŐRI R. (2006a), Bécs kapujában (Területi fejlettségi különbségek a Kisalföld déli részén a XX. század elején) [Vor den Toren von Wien (Regionale Entwicklungsunterschiede im südlichen Teil des Kleinen Ungarischen Tieflandes zu Beginn des 20. Jahrhunderts)]. In: Korall, 24, S. 231-250.

GYŐRI R. (2006b), A határ két oldalán. Városi vonzáskörzetek és a trianoni határmegvonás a Nyugat-Dunántúlon [Zu beiden Seiten der Grenze. Städtische Einzugsbereiche und 
die Trianoner Grenzziehung in Westtransdanubien]. In: GYőRI R., HaJdú Z. (Hrsg.), Kárpát-medence: települések, tájak, régiók, térstruktúrák, S. 279-292. Budapest - Pécs, Dialóg-Campus Kiadó.

Haggett P. (2001), Geography. A Global Synthesis. Essex, Pearson.

HARDI T. (2005), Határon átnyúló ingázás, munkavállalás az osztrák-magyar határtérségben [Grenzüberschreitendes Pendeln, Arbeiten in der österreichisch-ungarischen Grenzregion]. In: Tér és Társadalom, 19, 2, S. 65-81.

Haslinger P. (1996), Das Burgenland - Ein Faktor in den bilateralen Beziehungen zwischen Österreich und Ungarn 1921-1938. In: WIDDER R. (Hrsg.), Burgenland 1921. Anfänge, Übergänge, Aufbau (= Wiss. Arbeiten aus dem Burgenland, 95), S. 99-119.

Havličé T., Chromý P., Jančak V., Marada M. (2008), Innere und äußere Peripherie am Beispiel Tschechiens. In: Mitt. d. Österr. Geogr. Ges., 150, S. 299-316.

Katus L. (1979), A tőkés gazdaság fejlődése a kiegyezés után [Entwicklung der Geldwirtschaft nach dem Ausgleich]. In: Kovács E., Katus L. (Hrsg.), Magyarország története 1848-1890, Budapest (= Magyarország története tíz kötetben, 6, 2), S. 913-1038.

Katus L. (1988), Magyarország gazdasági fejlődése [Entwicklung der ungarischen Wirtschaft]. In: Hanák P., Mucsi F. (Hrsg.), Magyarország története 1890-1918, Budapest (= Magyarország története tíz kötetben, 7,1), S. 263-292, 338-401.

KirnBAUER S. (1977), Bevölkerungs- und Siedlungsgeographie des Burgenlandes. In: Geogr. Jahrbuch Burgenland, 1, S. 101-164.

KnABL W. (1977), Veränderungen in der Wirtschaftsstruktur des Burgenlandes von 1921 bis 1964. In: Geogr. Jahrbuch Burgenland, 1, S. 13-64.

KovÁcs Z. (1990), A határ menti területek központhálózatának átalakulása az elsố világháború utántól napjainkig [Die Entwicklung des Zentrennetzes in den grenznahen Gebieten seit dem Ende des Zweiten Weltkrieges bis heute]. In: Földrajzi Közlemények, 114, 1-2, S. 3-16.

KöZponti Statisztikai Hivatal (KSH) (Hrsg.) (1950a), 1949. évi Népszámlálás. Demográfiai eredmények [Volkszählung 1949. Daten zur Bevölkerung]. Budapest.

Központi Statisztikai Hivatal (KSH) (Hrsg.) (1950b), 1949. évi Népszámlálás. Részletes épület- és lakásstatisztikai eredmények [Volkszählung 1949. Daten zu Gebäuden und Wohnungen]. Budapest

KöZponti Statisztikai Hivatal (KSH) (Hrsg.) (1962a), 1960. évi Népszámlálás 3h kötet GyőrSopron megye személyi és családi adatai [Volkszählung 1960. Bd.3h. Daten zur Person und Familie im Komitat Raab-Ödenburg]. Budapest.

Központi Statisztikai Hivatal (KSH) (Hrsg.) (1962b), 1960. évi Népszámlálás 3k kötet Vas megye személyi és családi adatai [Volkszählung 1960. Bd. 3k. Daten zur Person und Familie im Komitat Eisenburg]. Budapest.

KöZPonti Statisztikai Hivatal (KSH) (Hrsg.) (1962c), 1960. évi Népszámlálás 31 kötet Veszprém megye személyi és családi adatai [Volkszählung 1960. Bd. 31. Daten zur Person und Familie im Komitat Veszprém]. Budapest.

KöZponti Statisztikai Hivatal (KSH) (Hrsg.) (1962d), 1960. évi Népszámlálás 8. kötet A lakások és lakóházak adatai [Volkszählung 1960. Bd. 8. Daten zu Wohnungen und Wohnhäusern]. Budapest.

KöZponti Statisztikai Hivatal (KSH) (Hrsg.) (1971a), 1970. évi Népszámlálás. Győr-Sopron megye adatai [Volkszählung 1970. Daten im Komitat Raab-Ödenburg]. Budapest.

KöZPonti Statisztikai Hivatal (KSH) (Hrsg.) (1971b), 1970. évi Népszámlálás. Vas megye adatai [Volkszählung 1970. Daten im Komitat Eisenburg]. Budapest.

KöZponti Statisztikai Hivatal (KSH) (Hrsg.) (1981a), 1980. évi Népszámlálás. Győr-Sopron megye adatai [Volkszählung 1980. Daten im Komitat Raab-Ödenburg]. Budapest. 
Központi Statisztikai Hivatal (KSH) (Hrsg.) (1981b), 1980. évi Népszámlálás. Vas megye adatai [Volkszählung 1980. Daten im Komitat Eisenburg]. Budapest.

KöZponti Statisztikai Hivatal (KSH) (Hrsg.) (1992a), 1990. évi Népszámlálás. Győr-Sopron megye adatai [Volkszählung 1990. Daten im Komitat Raab-Ödenburg]. Budapest.

Központi Statisztikai Hivatal (KSH) (Hrsg.) (1992b), 1990. évi Népszámlálás. Vas megye adatai [Volkszählung 1990. Daten im Komitat Eisenburg]. Budapest.

KöZponti S tatisztikai Hivatal (KSH) (Hrsg.) (2002a), 2001. évi népszámlálás. Területi adatok Győr-Moson Sopron megye, II. Kötet [Volkszählung 2001. Regionale Daten im Komitat Raab-Wieselburg-Ödenburg, Bd. 2]. Budapest.

KöZponti Statisztikai Hivatal (KSH) (Hrsg.) (2002b), 2001. évi népszámlálás. Területi adatok Vas megye II. Kötet [Volkszählung 2001. Regionale Daten im Komitat Eisenburg, Bd. 2]. Budapest.

KöZponti Statisztikai Hivatal (KSH) (Hrsg.) (2002c), 2001. évi népszámlálás. Területi adatok Veszpérm megye II. Kötet [Volkszählung 2001. Regionale Daten im Komitat Veszprém, Bd. 2]. Budapest.

Lichtenberger E. (2002), Österreich. Darmstadt, Wiss. Buchges.

Magyar Királyi Központi Statisztikai Hivatal (MKKSH) (Hrsg.) (1912a), A Magyar Szent Korona országainak 1910. évi népszámlálása. I. rész. (A népesség fóbb adatai) [Die Volkszählung in den Ländern der Ungarischen Heiligen Krone von 1910. 1. Teil (Hauptdaten zur Bevölkerung)] (= Magyar Statisztikai Közlemények. Új sorozat, 42). Budapest.

Magyar Királyi Központi Statisztikai Hivatal (MKKSH) (Hrsg.) (1912b), Népmozgalom 1901-1910 [Bevölkerungsentwicklung 1901-1910)] (= Magyar Statisztikai Közlemények. Új sorozat, 46). Budapest.

Magyar Királyi Központi Statisztikai Hivatal (MKKSH) (Hrsg.) (1913), A Magyar Szent Korona országainak 1910. évi népszámlálása. II. rész. (A népesség foglalkozása és a nagyipari vállalatok községenként) [Die Volkszählung in den Ländern der Ungarischen Heiligen Krone von 1910.2. Teil (Berufe der Einwohner und die Unternehmen der Großindustrie pro Gemeinde)] (= Magyar Statisztikai Közlemények. Új sorozat, 48). Budapest.

Magyar KirÁLYi PÉNZÜgYMiniszTérium (MKP) (Hrsg.) (1914a), Győr vármegye adóközségeinek területe és kataszteri tiszta jövedelme mívelési áganként és osztályonként az 1909. évi V. t.-czikk alapján végrehajtott kiigazítás után. [Ausdehnung des Steuerbezirkes und reines Katastereinkommen pro Produktionszweig für das Komitat Raab nach der Berichtigung aufgrund der Gesetzesnovelle Nr. 5 von 1909]. Budapest.

Magyar KirÁlyi PénZÜgYminisZtérium (MKP) (Hrsg.) (1914b), Moson vármegye adóközségeinek területe és kataszteri tiszta jövedelme mívelési áganként és osztályonként az 1909. évi V. t.-czikk alapján végrehajtott kiigazítás után. [Ausdehnung des Steuerbezirkes und reines Katastereinkommen pro Produktionszweig für das Komitat Wieselburg nach der Berichtigung aufgrund der Gesetzesnovelle Nr. 5 von 1909]. Budapest.

Magyar KiRÁlyi PénZÜgYminisztérium (MKP) (Hrsg.) (1914c), Sopron vármegye adóközségeinek területe és kataszteri tiszta jövedelme mívelési áganként és osztályonként az 1909. évi V. t.-czikk alapján végrehajtott kiigazítás után. [Ausdehnung des Steuerbezirkes und reines Katastereinkommen pro Produktionszweig für das Komitat Ödenburg nach der Berichtigung aufgrund der Gesetzesnovelle Nr. 5 von 1909]. Budapest.

Magyar KirÁlyi PÉNZÜGyminiszTérium (MKP) (Hrsg.) (1914d), Vas vármegye adóközségeinek területe és kataszteri tiszta jövedelme mívelési áganként és osztályonként az 1909. évi V. t.-czikk alapján végrehajtott kiigazítás után. [Ausdehnung des Steuerbezirkes und reines Katastereinkommen pro Produktionszweig für das Komitat Eisenburg nach der Berichtigung aufgrund der Gesetzesnovelle Nr. 5 von 1909]. Budapest. 
Magyar KiRÁLyi PénZÜG yminiszTérium (MKP) (Hrsg.) (1914e), Veszprém vármegye adóközségeinek területe és kataszteri tiszta jövedelme mívelési áganként és osztályonként az 1909. évi V.t.-czikk alapján végrehajtott kiigazítás után. [Ausdehnung des Steuerbezirkes und reines Katastereinkommen pro Produktionszweig für das Komitat Veszprém nach der Berichtigung aufgrund der Gesetzesnovelle Nr. 5 von 1909]. Budapest.

MichalKó G. (2004), A bevásárlóturizmus [Der Einkaufstourismus]. Székesfehérvár, Kodolányi János Fő́iskola.

Mitterbach J. (1949), Das geographische Moment in Grenzziehungsproblemen. In: Mitt. d. Geogr. Ges. in Wien, 91, S. 215-217.

NAGY M. (2003), A magyar mezőgazdaság regionális szerkezete a 20. század elején [Die regionale Struktur der ungarischen Landwirtschaft zu Beginn des 20. Jahrhunderts]. Budapest.

Österreichisches Statistisches Zentralamt (ÖSTAT) (Hrsg.) (1952a), Ergebnisse der Volkszählung vom 1. Juni 1951 nach Gemeinden. Burgenland. Wien.

Österreichisches Statistisches Zentralamt (ÖSTAT) (Hrsg.) (1952b), Ergebnisse der Häuserund Wohnungszählung vom 1. Juni 1951 nach Gemeinden. Burgenland. Wien.

Österreichisches Statistisches Zentralamt (ÖSTAT) (Hrsg.) (1963a), Ergebnisse der Volkszählung vom 21. März 1961. Burgenland. Wien.

Österreichisches Statistisches Zentralamt (ÖSTAT) (Hrsg.) (1963b), Ergebnisse der Häuserund Wohnungszählung vom 21. März 1961. Burgenland. Wien.

Österreichisches Statistisches Zentralamt (ÖSTAT) (Hrsg.) (1972), Ergebnisse der Volkszählung vom 12. Mai 1971. Burgenland. Wien.

Österreichisches Statistisches Zentralamt (ÖSTAT) (Hrsg.) (1973), Ergebnisse der Häuserund Wohnungszählung vom 12. Mai 1971. Hauptergebnisse für Burgenland. Wien.

Österreichisches Statistisches Zentralamt (ÖSTAT) (Hrsg.) (1982), Häuser- und Wohnungszählung 1981. Hauptergebnisse Burgenland. Wien.

Österreichisches Statistisches Zentralamt (ÖSTAT) (Hrsg.) (1985), Volkszählung 1981. Hauptergebnisse II. Burgenland. Wien.

Österreichisches Statistisches Zentralamt (ÖSTAT) (Hrsg.) (1992), Häuser- und Wohnungszählung 1991. Hauptergebnisse Burgenland. Wien.

Österreichisches Statistisches Zentralamt (ÖSTAT) (Hrsg.) (1995), Volkszählung 1991. Hauptergebnisse II. Burgenland. Wien.

Paschinger V. (1919), Grenzformulierungen im Süden Deutschösterreichs. In: Mitt. d. Geogr. Ges. in Wien, 62, S. 277-283.

Penz H. (1997), Die Stellung der Landwirtschaft im Modernisierungsprozess Österreichs nach dem Zweiten Weltkrieg. In: Mitt. d. Österr. Geogr. Ges., 139, S. 77-100.

Penz H. (2008), 90 Jahre Brennergrenze. Zur Bedeutung der Grenze für regionale Differenzierungsprozesse in der Brennergegend von der Teilung Tirols (1919) bis zur gegenwärtigen Zusammenarbeit im Rahmen der EU. In: Mitt. d. Österr. Geogr. Ges., 150, S. 75-98.

Polsterer A. (red.) (2002), Grenzüberschreitende Arbeitsmarktbeziehungen zwischen Burgenland und Westungarn. Sozial- u. Wirtschaftswiss. Forschungsinst. d. ungar. Gewerkschaften - Burgenländ. Forschungsges., Eisenstadt - Győr - Budapest. - http://www.forschungs gesellschaft.at [Abruf: 10.09.2007].

Seger M. (1993), Problemaufgriff, Methoden und Regionalbezug. In: Seger M., Beluszky P. (Hrsg.), Bruchlinie Eiserner Vorhang. Regionalentwicklung im österreichisch-ungarischen Grenzraum (Südburgenland/Oststeiermark - Westungarn), S. 1-33. Wien - Köln - Graz, Böhlau Verlag.

Seger M., Beluszky P., Sikos T.T. (1993), Der Regional- und Systemvergleich nach sozioökonomischen Merkmalen: Prozesse und Strukturen. In: Seger M., Beluszky P. (Hrsg.), Bruchlinie Eiserner Vorhang. Regionalentwicklung im österreichisch-ungarischen Grenzraum 
(Südburgenland/Oststeiermark - Westungarn), S. 35-97, Wien - Köln - Graz, Böhlau Verlag.

Sölch J. (1923), Geographische Kräfte im Schicksal Tirols. In: Mitt. d. Geogr. Ges. in Wien, 66, S. 13-45.

Statistik Austria (SA) (Hrsg.) (2002a), Volkszählung 2001. Hauptergebnisse I. - Burgenland. Wien.

Statistik Austria (SA) (Hrsg.) (2002b), Volkszählung 2001. Hauptergebnisse II. - Burgenland. Wien.

Statistik Austria (SA) (Hrsg.) (2002c), Volkszählung 2001. Wohnbevölkerung nach Gemeinden (Mit Bevölkerungsentwicklung seit 1869). Wien.

Statistik Austria (SA) (Hrsg.) (2004), Gebäude- und Wohnungszählung 2001. Hauptergebnisse Burgenland. Wien.

Strohmayer U. (2009), Modernization. In: Derek G., Johnston R., Pratt M.J., Whatmore S (Hrsg.), The Dictionary of Human Geography, 5. Aufl., S. 474-475. Chichester, WileyBlackwell.

TiтZ N. (1977), Zur Wirtschaftsentwicklung des Burgenlandes. In: Geogr. Jahrbuch Burgenland, 1, S. $65-100$.

Tóтн I. (2006), A nyugat-magyarországi kérdés 1922-1939. Diplomácia és helyi politika a két világháború között [Die westungarische Frage 1922-1939. Diplomatie und Regionalpolitik zwischen den Weltkriegen]. Sopron.

Trummer K. (1995), Das mittlere Burgenland zwischen Ostöffnung und EU-Beitritt. In: Geogr. Jahrbuch Burgenland, 19, S. 10-33.

VöRös A. (1988), A mezógazdaság [Die Landwirtschaft]. In: Hanák P., Mucsi F. (Hrsg.), Magyarország története 1890-1918 (Magyarország története tíz kötetben 7/1), S. 293-338. Budapest.

WINDISCH E. (1991), Das südliche Burgenland - eine Regionalgeographie. In: Geogr. Jahrbuch Burgenland, 15, S. 47-58. 